2020-02-01

Infragravity wave generation on shore platforms: Bound long wave versus breakpoint forcing

\title{
Poate, Tim
}

http://hdl.handle.net/10026.1/15631

\subsection{6/j.geomorph.2019.106880}

Geomorphology

Elsevier BV

All content in PEARL is protected by copyright law. Author manuscripts are made available in accordance with publisher policies. Please cite only the published version using the details provided on the item record or document. In the absence of an open licence (e.g. Creative Commons), permissions for further reuse of content should be sought from the publisher or author. 


\title{
Infragravity wave generation on shore platforms: Bound long wave versus breakpoint forcing
}

\author{
Tim Poate ${ }^{\mathrm{e}, *}$, Gerd Masselink ${ }^{\mathrm{e}, *}$, Martin J. Austin ${ }^{\mathrm{a}}$, Kris Inch ${ }^{\mathrm{b}}$, Mark Dickson ${ }^{\mathrm{c}}$, \\ Robert McCall ${ }^{\mathrm{d}}$ \\ a School of Ocean Sciences, Bangor University, Wales, United Kingdom \\ ${ }^{\mathrm{b}}$ Environment Agency, UK \\ c School of Environment, The University of Auckland, New Zealand \\ d Deltares, Boussinesqweg 1, 2629 HV, Delft, the Netherlands \\ e Coastal Processes Research Group, School of Biological and Marine Sciences, University of Plymouth, Plymouth, UK
}

\section{A R T I C L E I N F O}

\section{Article history:}

Received 15 May 2019

Received in revised form

17 September 2019

Accepted 19 September 2019

Available online 23 October 2019

\section{Keywords:}

Shore platforms

Infragravity

Wave transformation

\begin{abstract}
A B S T R A C T
Shore platforms are ubiquitous morphological features along rocky coastlines and display a spectrum of forms from gently-sloping to sub-horizontal with a low tide cliff. They generally front eroding coastal cliffs and play an important natural coastal protection role by dissipating wave energy, especially during energetic wave conditions. Sea-swell wave energy dissipates during wave breaking, but the transfer of incident wave energy to lower frequencies, resulting in infragravity waves, can enable significant amounts of wave energy to persist up to the shoreline. This residual wave motion at the shoreline can carry out geomorphic work, for example by directly impacting the cliff face, but also for removing cliff-toe debris. There are two main mechanisms for generating infragravity wave motion - group bound long waves and breakpoint forcing - and it is not known which of these mechanisms operate on shore platforms. Here we show, using field data collected at a sloping platform in England and a sub-horizontal platform in New Zealand, and supported by numerical modelling, that the group bound long wave mechanism is most important on sloping platforms, whereas breakpoint forcing dominates on sub-horizontal platforms. Our results also suggest that the infragravity wave motion on the sloping platform is somewhat more energetic than that on the sub-horizontal platform, implying that the latter type of platform may provide better protection to coastal cliffs. However, site-specific factors, especially platform elevation with respect to tidal level and platform gradient, play a key role in wave transformation processes on shore platforms and more field data and modelling efforts are required to enhance our understanding of these processes, especially collected under extreme wave conditions $\left(H_{s}>5 \mathrm{~m}\right)$.
\end{abstract}

(C) 2019 Elsevier B.V. All rights reserved.

\section{Introduction}

Shore platforms exist within a continuum of forms and are typically observed as (quasi-) horizontal or low gradient $(\tan \beta<0.05)$ rocky surfaces that occur within or close to the intertidal zone of rocky coasts and are commonly backed by cliffs (Trenhaile, 1987; Sunamura, 1992). The surface of shore platforms ranges from very smooth (like a sandy beach) to very rough and depends on geological factors such as the lithology and stratigraphic characteristics of the bed. Shore platforms are of particular interest to coastal scientists as they directly control the transformation of waves prop-

\footnotetext{
* Corresponding authors.

E-mail addresses: Timothy.poate@plymouth.ac.uk (T. Poate), gerd.masselink@plymouth.ac.uk(G. Masselink).
}

agating across its surface (e.g., Farrell et al., 2009; Ogawa et al., 2011; Poate et al., 2018), and thus the amount of wave energy reaching the base of coastal cliffs. In turn, this is important in driving coastal cliff recession rates, but rock platforms also provide key evidence for the age, inheritance and mode of development of rocky coasts. Although existing across a spectrum of forms, two endmember types of shore platform have been commonly described in previous studies (e.g., Sunamura, 1992): Type A platforms are gently sloping $(\tan \beta \approx 0.01-0.05)$ and usually extend into the subtidal zone and Type B platforms are sub-horizontal with a low tide cliff or reef-type feature, the upper part of which can sometimes be seen at low tide (Kennedy, 2016). Shore platform type appears predominantly controlled by tidal range (Trenhaile, 1987) with sloping platforms typical of large tidal environments (mean spring tidal range $>2 \mathrm{~m}$ ) and sub-horizontal platforms more com- 
mon in regions with a small tidal range (mean spring tidal range $<2 \mathrm{~m}$ ). However, the balance of rock resistance versus wave force is also highly significant (Sunamura, 1992) and sea level history and morphological inheritance also provide important controls on shore platform geometry (e.g., Stephenson et al., 2017).

Infragravity waves are low frequency $(0.005-0.04 \mathrm{~Hz} ; 20-200 \mathrm{~s})$ waves that can dominate the spectrum of water motions and sediment transport processes within the inner surf zone (Bertin et al., 2018). There are two widely accepted mechanisms for the generation of infragravity waves, both related to the variation in sea-swell energy induced by wave groups. The first theory for infragravity wave generation was proposed by Biesel (1952), and later by Longuet-Higgins and Stewart (1962) and Hasselmann (1962), who demonstrated theoretically that the modulation of short wave height by wave groups induces a variation in water level causing it to become depressed under groups of large waves, and enhanced where the sea-swell waves are smaller. This variation in water level creates a second-order wave that is 'bound' to the wave groups. The bound infragravity wave propagates at the group velocity and has the same wavelength and period as the wave groups, but is $180^{\circ}$ out of phase (i.e., the trough of the bound infragravity wave is coincident with the largest waves in the wave group). It is commonly assumed that the bound long wave is released by short-wave breaking and continues to propagate to the shore as a free wave (e.g., Masselink, 1995; Inch et al., 2017). The second generation mechanism, proposed by Symonds et al. (1982), is the time-varying breakpoint in which freely propagating infragravity waves are generated as dynamic set-up/down oscillations as a result of the spatially fluctuating breakpoint of different sized wave groups. According to this mechanism two infragravity waves are generated, both originating at the sea-swell wave breakpoint and with the same frequency as the wave groups: a set-up wave propagating to the shore (in phase with wave groups) and a set-down wave travelling out to sea (in anti-phase with wave groups).

Laboratory studies have demonstrated that the relative importance of the two generation mechanisms is largely controlled by the beach slope, with bound infragravity waves dominating on mild sloping beaches, and steeper beaches being more conducive to breakpoint generated infragravity waves (e.g., Battjes et al., 2004; Van Dongeren et al., 2007). In addition to bed slope, sea-swell wave steepness has also been shown to have an influence on the generation of infragravity waves (Baldock and Huntley, 2002; Baldock, 2012).

Energetic infragravity wave motions have been suggested as a mechanism to perform geomorphic work, for example by directly impacting the cliff face, and for removing cliff-toe debris (Dickson et al., 2013). Additionally, infragravity waves may increase the level of sea-swell energy at the base of cliffs backing shore platforms by reducing short-wave dissipation through the increase in the local water depth under the infragravity wave crests (i.e., relatively large sea-swell waves 'ride' the infragravity wave crests). However, to date, detailed infragravity wave studies have focused primarily on sandy beaches.

Some of the data presented here have previously been used to quantify incident wave dissipation and platform roughness effects (Poate et al., 2016, 2018) and to model incident and infragravity wave signals (McCall et al., 2017), however, prior to these, few published studies have focused on infragravity wave transformation over rocky shore platforms. Beetham and Kench (2011) undertook two field experiments on sub-horizontal shore platforms in New Zealand, however, the study was relatively modest in its analysis and experimental set-up as data were only collected by five pressure sensors deployed for up to $36 \mathrm{~h}$, and wave conditions were low-moderate with maximum offshore wave heights not exceeding $1.5 \mathrm{~m}$. The results of this study were mostly consistent with those from sandy beaches, with infragravity wave height linearly dependent on the offshore sea-swell wave height and increasing shoreward with a maximum infragravity wave height of $0.20 \mathrm{~m}$ close to shore. Infragravity wave shoaling, quantified as the change in wave height from the platform edge to the cliff toe, was strongest on the wider of the two platforms. A shoreward increase in infragravity wave height and the increasing significance of infragravity energy relative to sea-swell energy on the inner platform, analogous to dissipative sandy beaches, has also been observed on other sub-horizontal shore platforms in New Zealand and in Australia by Marshall and Stephenson (2011) and Ogawa et al. (2011, 2015).

Coral reefs have a morphology that is analogous to subhorizontal shore platforms, with a relatively horizontal reef flat and a low tide reef step, and have been the subject of several infragravity wave studies (e.g., Lugo-Fernandez et al., 1998; Brander et al., 2004; Pomeroy et al., 2012; Pequignet et al., 2014; Cheriton et al., 2016; Masselink et al., 2019). Coral reefs exist primarily in microtidal regions and have a large bed roughness, and thus friction coefficient, compared to sandy beaches. On a fringing reef in Western Australia, Pomeroy et al. (2012) found that the water motion shoreward of the reef crest was dominated by infragravity waves and that the dominant generation mechanism of the infragravity waves was the time-varying breakpoint at the steep reef crest. This was supported by numerical simulations and is consistent with the theory that breakpoint-generated infragravity waves are more prevalent in steep sloping regimes. The efficiency of the time-varying breakpoint for infragravity wave generation was also observed on coral reefs by Pequignet et al. (2009, 2014) and Becker et al. (2016), and in numerical modelling by Van Dongeren et al. (2013) and Masselink et al. (2019).

Whilst a number of studies have investigated infragravity waves on sub-horizontal shore platforms and similar coral reefs, there are few studies from sloping shore platforms. In a study of wave transformation at five sloping shore platforms around the UK, Poate et al. (2018) observed the total infragravity energy to either remain constant or decrease in the shoreward direction through bed roughness. This characteristic of infragravity waves on rocky platforms, generated by bound wave theory, was supported by Jager (2016), based on the analysis of the field data collected on one of these sloping platforms and supported by XBeach numerical modelling. Recently, an approximate $10 \%$ increase in total infragravity energy was observed across a sloping platform in a macro-tidal setting by Stephenson et al. (2018); however, low-energy wave conditions, measurements at only three cross-shore locations and a largely qualitative analysis limit the ability of their study to elucidate more fully the geomorphic significance of infragravity waves on such platforms.

This paper investigates and compares the generation and transformation of infragravity waves on contrasting sub-horizontal and sloping shore platforms. Field data from a sub-horizontal platform at Leigh, New Zealand, and a sloping platform at Lilstock, UK, are analysed and complimented by numerical modelling using the XBeach model (phase-resolving). The specific objectives of this study are to: (1) assess the relative importance of the bound wave and the time-varying breakpoint theories of infragravity wave generation on the two platforms; (2) investigate and quantify the transformation of infragravity energy across the platforms; and (3) discuss the geomorphic implications of the findings.

\section{Methodology}

\subsection{Site description}

Data presented in this paper originate from two field sites: Lilstock (LST) in Somerset, UK, and Tatapouri (TAT) on the east coast of the North Island in New Zealand (Fig. 1). Both sites are part of 

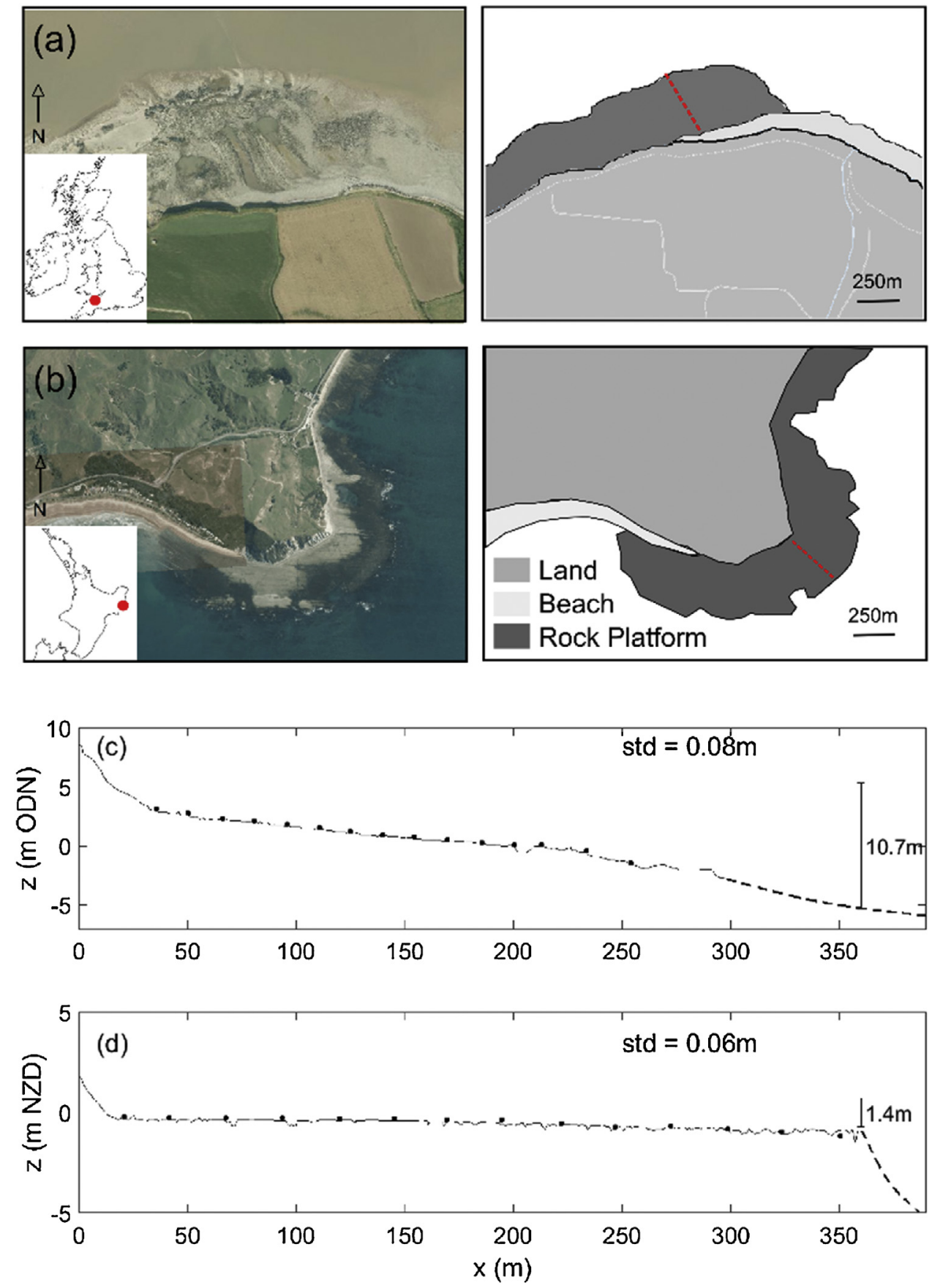

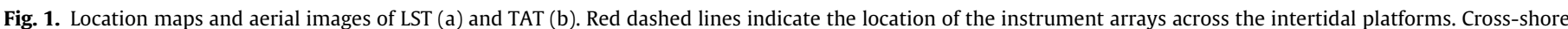

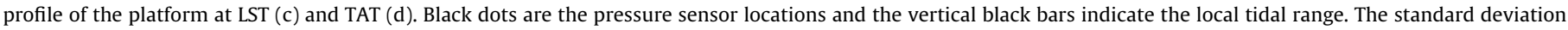
(std) of the profile surface is provided as an indication of relative roughness. Note the different axis limits. Dashed line indicates un-surveyed section of profile.

a larger project looking at wave transformation across rocky platforms, with data from LST presented in Poate et al. $(2016,2018)$ and McCall et al. (2017). LST experiences macrotidal conditions, with a mean spring range of $10.7 \mathrm{~m}$, and is characterised by a wide $(300 \mathrm{~m})$, rather smooth and uniformly sloping platform $(\tan \beta=0.021)$. The platform at TAT has a microtidal regime with a $1.4 \mathrm{~m}$ mean spring range and is characterised by two distinct slopes with a smooth, upper sub-horizontal section ( $\tan \beta=0.0004$ ) that extends $\sim 150 \mathrm{~m}$ before a break in slope where the profile drops away more rapidly $(\tan \beta=0.002)$ over the lower $150 \mathrm{~m}$. The profiles presented in Fig. 1 show the surveyed intertidal portion of the survey area. Extended profiles, highlighting the steep gradient at the edge of the platform at TAT, are presented later in Section 3.3.
The site at LST is located on the southern side of the Bristol Channel, orientated north, making it relatively sheltered from the dominant south-westerly waves moving in from the North Atlantic. The profile itself is composed of sub-horizontal, c. 0.4-m thick mudstone beds which, through variable exposure and erosion, results in pools and shallow channels (Fig. 2c). The field site at TAT is located on the east coast of the North Island exposed to the Pacific Ocean with incident swell approaching from the south-east (Ogawa et al., 2011). The wide, sub-horizontal platform is dominated by siltstone interbedded with weathered sandstone, which leaves shallow pools and crevices (Fig. 2a). Due to the sub-horizontal bedding planes at both sites, the shore platform surfaces are relatively smooth, minimising frictional wave 


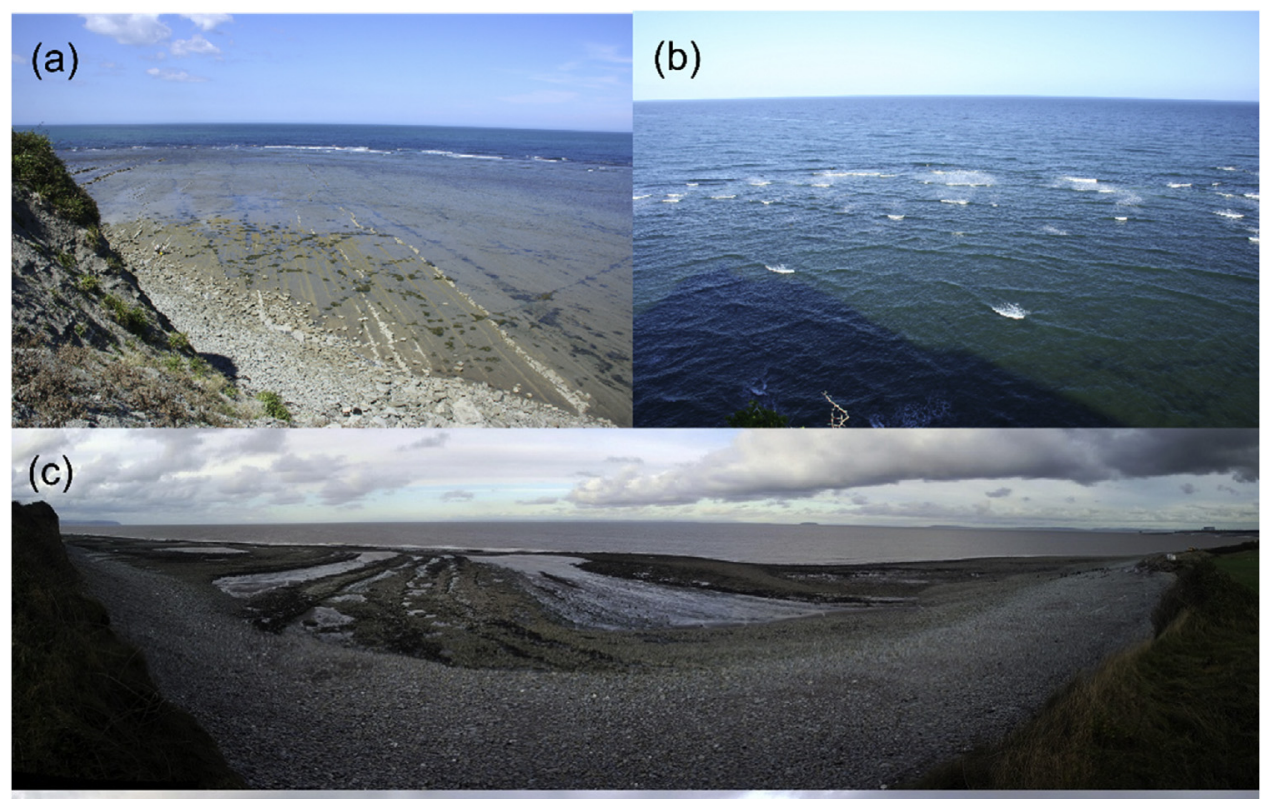

(d)

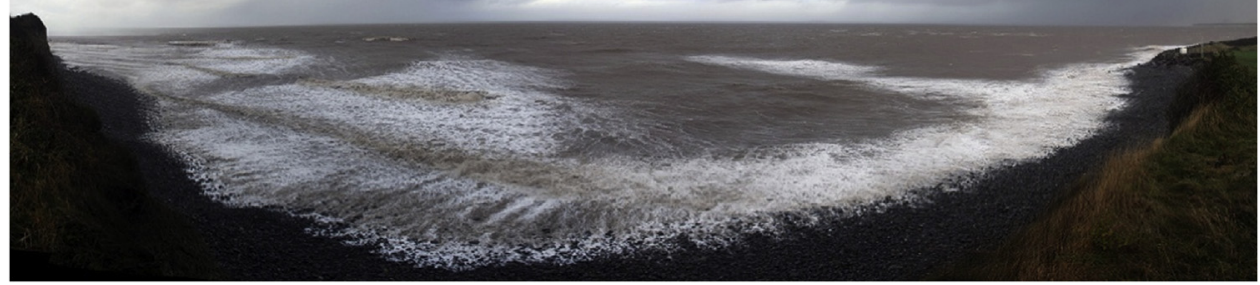

Fig. 2. Site photos at low tide and high tide at TAT ( $a$ and b) and LST (c and d).

energy dissipation during wave transformation (cf., Poate et al., 2018).

\subsection{Data collection}

For each site, a detailed topographic survey was undertaken across the intertidal platform using RTK GPS (LST) and a total station (TAT). Each dataset was transformed onto a local coordinate system as shown in Fig. 1. To provide a comparison of platform roughness, the standard deviation was calculated for a detrended profile using a 5-m moving window. The mean value of this is presented in Fig. 1 and shows that LST $(0.08 \mathrm{~m})$ exhibited a slightly larger mean value compared TAT $(0.06 \mathrm{~m})$, and is hence somewhat rougher.

Hydrodynamic data were collected over eight tides from the $8^{\text {th }}$ December 2014 at LST and over six tides from the $24^{\text {th }}$ February 2016 at TAT. At each site, a linear array of RBR Solo pressure sensors (15 at LST and 14 at TAT) were housed within steel tubes $(0.23 \mathrm{~m}$ long) and fixed to the platform surface using bolts or heavy weights. The sensors logged continuously at $8 \mathrm{~Hz}$ and were evenly spaced across the platforms between the low- and high-water lines. Each sensor was surveyed in position using the GPS or total station for vertical precision.

At TAT, a $1200 \mathrm{kHz}$ Teledyne Workhorse ADCP was deployed on the seabed (looking up) $\sim 300 \mathrm{~m}$ from the edge of the platform in 8-10 $\mathrm{m}$ water depth to measure the nearshore wave climate. The ADCP was configured for burst sampling, recording 2400samples at a rate of $2 \mathrm{~Hz}$ every $20 \mathrm{~min}$. At LST, offshore wave conditions were not available and therefore the outermost PT has been used to represent boundary conditions (when this PT was outside the surf zone). Table 1 provides a summary of the experimental set-up and platform morphology associated with the two field experiments.

\subsection{Analysis methods}

The local barometric pressure logged when each pressure sensor was exposed at low water was used to convert the absolute pressure to water surface elevation, and linear wave theory was used to correct for depth attenuation. The results presented herein are based on the analysis of $\sim 17$-min data segments ( 8192 data points), which provided a suitable compromise between tidal stationarity and being able to obtain representative statistical parameters. Bursts that were found to be intermittently wet and dry were excluded from analyses.

Auto-spectra were computed using Hanning-windowed, 50\% overlapping segments of 2048 points, providing 12 degrees of freedom (Nutall, 1971) and a frequency resolution $d f$ of $0.0039 \mathrm{~Hz}$. Infragravity $(0.005-0.05 \mathrm{~Hz})$ and sea-swell $(0.05-0.33 \mathrm{~Hz})$ significant wave heights ( $H_{\text {inf }}$ and $H_{s s}$, respectively) were calculated as

$H_{\text {inf }}=4 \sqrt{\int_{0.005}^{0.05} E(f) d f}$

and

$H_{S S}=4 \sqrt{\int_{0.05}^{0.33} E(f) d f}$

where $E(f)$ is the spectral density at frequency $f$. The transition frequency of $0.05 \mathrm{~Hz}$ between infragravity and sea-swell waves was selected to be consistent with most previous studies and also corresponds to the spectral valley present in the spectra for the majority of bursts. The high frequency sea-swell cut-off of $0.33 \mathrm{~Hz}$ corresponds to an attenuation level of $>80 \%$ at the most seaward pressure 
Table 1

Summary statistics for the LST and TAT field experiments.

\begin{tabular}{|c|c|c|c|}
\hline Parameters & & LST & TAT \\
\hline \multirow[t]{5}{*}{ Deployment data } & Duration (tides) & 8 & 6 \\
\hline & \# PTs & 15 & 14 \\
\hline & PT spacing $(\mathrm{m})$ & $\sim 15$ & $\sim 25$ \\
\hline & PT $z$ range $(\min , \max ) \mathrm{m}$ ODN, $\mathrm{m}$ NZD & $-1.46,3.14$ & $-1.18,-0.22$ \\
\hline & PT $x$ range $(\mathrm{m})$ & 225 & 325 \\
\hline \multirow[t]{4}{*}{ Platform morphology } & Intertidal platform width (m) & 325 & 340 \\
\hline & Bedrock & Mudstone & Siltstone \\
\hline & Average $\tan \beta$ between PTs & 0.021 & 0.0004 \\
\hline & Mean spring tide range, mean low water spring (m) & $10.7,-5$ & 1.4 \\
\hline
\end{tabular}

Note: $\mathrm{PT}=$ pressure sensor, $\tan \beta=$ slope, $\mathrm{ODN}$ - ordnance datum Newlyn, NZVD = New Zealand Vertical Datum.

sensor during high tide at LST, and thus higher frequencies could not be resolved confidently.

The infragravity wave generation mechanism at the two study sites was investigated using cross-correlation analysis between the infragravity time series and the wave group envelope. This technique considers the relationship between two time series with zero mean by applying a time shift to one of the series and has been widely used in infragravity wave research (e.g., Masselink, 1995; Janssen et al., 2003; Pomeroy et al., 2012; Ruju et al., 2012; Inch et al., 2017; Masselink et al., 2019). The infragravity and sea-swell time series ( $\eta_{\text {inf }}$ and $\eta_{s s}$, respectively) were calculated using a frequency domain filter whereby the discrete Fourier transformation of the total water surface elevation time series is multiplied by a filter function that has a value of unity at the passband frequencies and zero at all other frequencies, before undergoing an inverse Fourier transformation back into the time domain. The wave group envelope $A(t)$ was calculated following the method of List (1991) as

$A(t)=\frac{\pi}{2}\left|\eta_{s s}(t)\right|_{\text {low }}$

where subscript low indicates a low pass filter of frequency $0.05 \mathrm{~Hz}$, and |..| represents the modulus. The wave group envelope reflects the modulation of sea-swell amplitude on the time scale of wave groups.

The cross-correlation is expressed as

$r(\tau)=\frac{\left\langle\eta_{\text {inf }}(t) A(t+\tau)\right\rangle}{\sigma_{\eta_{\text {inf }}} \sigma_{A}}$

where $\tau$ is a time shift, $\langle.$.$\rangle denotes a time-averaging operator, and$ $\sigma_{\eta_{\text {inf }}}$ and $\sigma_{A}$ are the standard deviations of $\eta_{\text {inf }}$ and $A$, respectively. If the infragravity waves are predominantly bound to the short-wave groups, then the cross-correlation coefficient at a time lag of zero $r_{0}$ will approach -1 because the two time series will theoretically be $180^{\circ}$ out of phase. The $95 \%$ confidence intervals on the zero correlation, calculated following Garrett and Toulany (1981) and Jenkins and Watts (1968), are \pm 0.02 at LST and \pm 0.04 at TAT, respectively.

The grouped nature of the sea-swell waves is investigated further by calculating the groupiness factor $G F$, proposed by List (1991), as

$G F=\frac{\sqrt{2 \operatorname{var}[A(t)]}}{\bar{A}(t)}$

where var is the variance and the overbar represents the mean. The groupiness factor provides a normalised value between 0 and 1 , with 1 representing maximum groupiness of the wave group envelope.

To better understand the infragravity wave characteristics on each of the platforms, it is important to know the relative location of the data, within the surf zone. Throughout the TAT dataset, $H_{s s}$ decreases from the seaward-most to the shoreward-most sensor for every data burst. This implies that the sea-swell wave break- point, through all tidal stages, is located in the unsurveyed $\sim 20 \mathrm{~m}$ zone between the seaward-most sensor and the platform edge, regardless of the water depth over the platform. This is consistent with visual observations during the field experiment, which indicate consistent sea-swell wave breaking at the platform edge (refer to Fig. 2b). Therefore, it is assumed that the location of the sea-swell wave breakpoint $x_{b}$ is at the platform edge, $20 \mathrm{~m}$ seaward of the seaward-most sensor. The shoreward limit of the surf zone $(x=0)$ was taken as the location where the water level at the shallowest sensor intersects with the shoreline profile, and thus the normalized surf zone location $x / x_{b}$ is obtained, where $x / x_{b}=0$ indicates the shoreline and $x / x_{b}=1$ represents the seaward edge of the surf zone.

At LST, visual observation of the data revealed a clear initial shoreward increase in $H_{s S}$ due to wave shoaling followed by a more rapid decay for the bursts close to high tide during all tides. Therefore, an average breaker coefficient $\gamma_{b}$, defined as $H_{s S} / h$ at the onset of short wave breaking, was defined for each tide. The mean $\gamma_{b}$ throughout all tides was 0.4 . Using $\gamma_{b}$, data are given a normalised surf zone position $h / h_{b}$, where $h_{b}$ is the water depth at the sea-swell wave break point defined as $h_{b}=H_{b} / \gamma_{b}$, where $H_{b}$ is the breaking sea-swell wave height. Given that the profile at LST is quite linear in the region of the pressure sensors (refer to Fig. 1c), it is assumed that $x / x_{b}=h / h_{b}$.

\subsection{XBeach modelling}

Numerical modelling is used to complement the field data analysis and help with the interpretation of the results, as well as extending the parameter space beyond the conditions experienced during the field experiments. Modelling of the rock shore platform hydrodynamics was conducted using the phase-resolving (i.e., nonhydrostatic) variant of the widely used and open-source XBeach model (Roelvink et al., 2009). For the comparison between field measurments and model results, the model was set up using the surveyed intertidal profile, extending down to low water, and then extended to ensure the boundary conditions were in $15 \mathrm{~m}$ water depth. For TAT, the depth at the offshore ADCP was used to interpolate the bathymetry towards the platform edge where it was merged with the survey data, based on local knowledge. At LST, nearshore bathymetry was extracted from United Kingdom Hydrographic Office (UKHO) data, interpolated onto a regular grid and merged with the intertidal survey. When exploring the parameter space, idealised platform profiles were used and the model domain was extended to $20 \mathrm{~m}$ water depth to accommodate for peak wave periods of up to $14 \mathrm{~s}$. The sloping platform (LST) was simply represented by a single gradient of 0.02 (1:50) extending $1000 \mathrm{~m}$ offshore to $z=-20 \mathrm{~m}$. The horizontal platform (TAT) was represented by a $150-\mathrm{m}$ wide section with a gradient of 0.005 (1:200), fronted by a steep 5-m cliff with a gradient of 1 , before extending offshore with the same gradient as the LST platform to $z=-20 \mathrm{~m}$. Both idealised profiles were backed by a $5-\mathrm{m}$ high cliff with a gradient of 

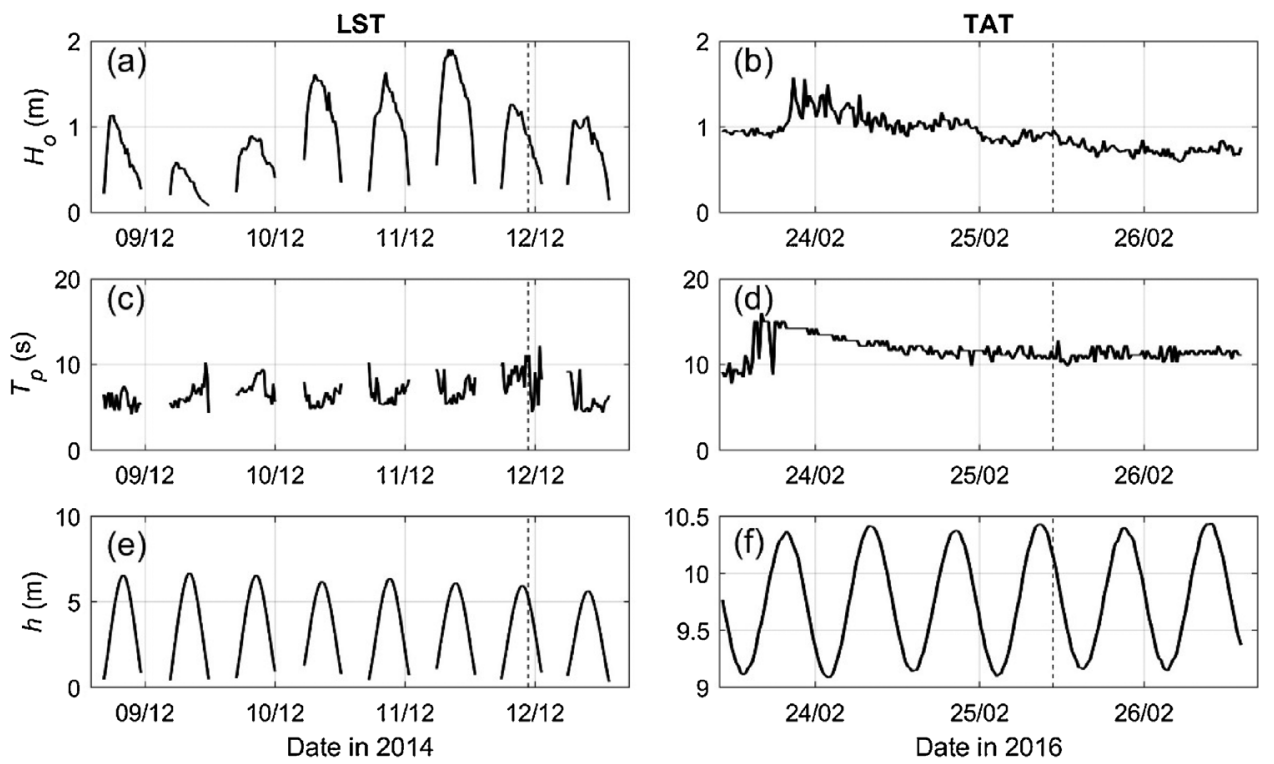

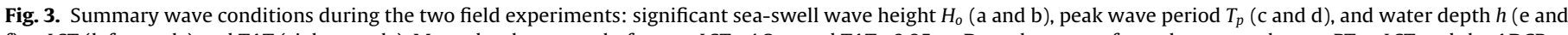

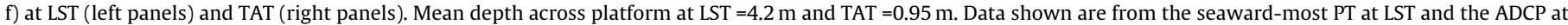
TAT. Vertical dashed lines indicate burst times used for subsequent analysis. Note the different axis limits between e and $\mathrm{f}$.

1. The profiles were constructed to resemble the natural profiles of Lilstock and Tatapouri, but with identical landward and seaward sections to avoid biasing the model results.

The numerical model was first validated using field observations with the natural platform profiles, and then used to generate an extended numerical data set for each of the field sites using the idealised platform profiles. To generate the extended numerical dataset, a constant water level was specified (SWL at the landward extend of the platforms; thus, at the base of the cliff) and $H_{O}$ and $T_{p}$ were varied, with $H_{o}$ ranging from 1 to $4 \mathrm{~m}$ at $1-\mathrm{m}$ increments and $T_{p}$ ranging from 6 to $14 \mathrm{~s}$ at 2 -s increments. The purpose of these model runs was to explore the $H_{0}-T_{p}$ parameter space beyond the field dataset and further examine the relationship between the infragravity wave height $H_{\text {inf }}$ and the wave power expression $H_{o}^{2} T_{p}$. In these simulations, the model was run using default parameters for a duration of $30 \mathrm{~min}$., with the initial $2 \mathrm{~min}$. used to allow the model to 'spin-up'. The modelled data were also decomposed into shoreward- and seaward-propagating infragravity components as was done, for example, in a similar numerical study of infragravity wave generation across coral reef platforms by Masselink et al. (2019) using the methodology of Guza et al. (1984).

\section{Results}

\subsection{Event summary}

Wave conditions at the seaward-most sensors during the LST and TAT field experiments are presented in Fig. 3. At LST, the largest values of $H_{0}$ were during the middle and latter half of the study period, during which $H_{0}$ exceeded $1 \mathrm{~m}$ at high tide at the seawardmost sensor, with a maximum value of $1.91 \mathrm{~m}$ during tide 6 . Peak wave periods ranged between 4 and $13 \mathrm{~s}$, with a mean of $6.7 \mathrm{~s}$. At TAT, $H_{o}$ measured at the ADCP ranged between 0.59 and $1.57 \mathrm{~m}$, peaking during tide 1 before decreasing for the remaining tides. Maximum and minimum peak wave periods were $7.8 \mathrm{~s}$ and $16.0 \mathrm{~s}$, respectively, also peaking during tide 1 . Mean $H_{s s}$ and $T_{p}$ at TAT were $0.92 \mathrm{~m}$ and $11.8 \mathrm{~s}$, respectively.

Maximum $H_{\text {inf }}$ on the LST platform was $0.34 \mathrm{~m}$, measured at the shallowest sensor during tide 6 when $H_{o}$ at the seaward-most sensor was largest. This is almost twice as large as the maximum $H_{\text {inf }}$

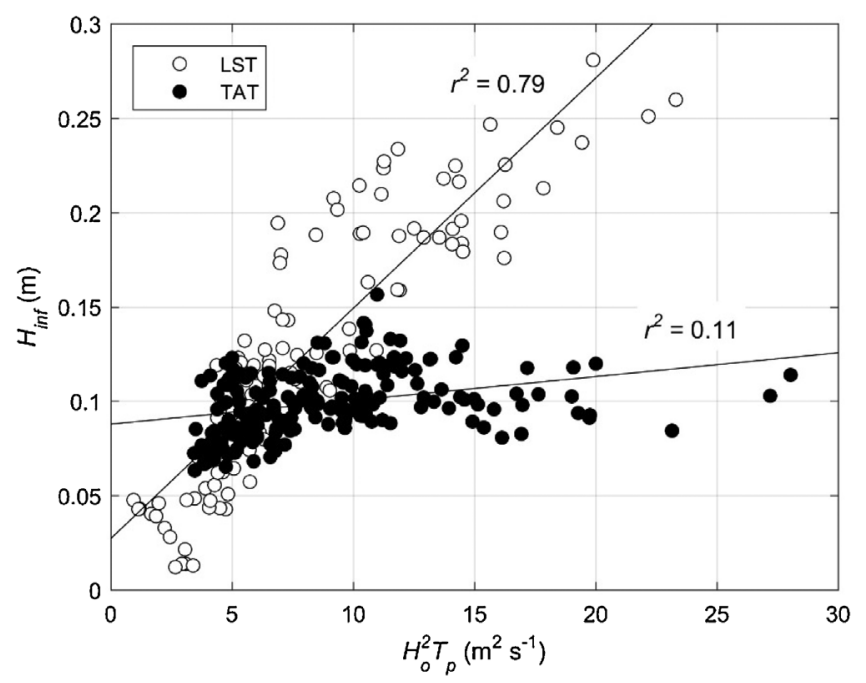

Fig. 4. Infragravity wave height $H_{\text {inf }}$ averaged across the surf zone versus $H_{o}^{2} T_{p}$ at LST (circles) and TAT (dots). Black lines are best-fit linear regression lines with coefficients of determination $r^{2}$ given in the figure.

measured on the TAT platform of $0.18 \mathrm{~m}$. This was also measured at the shallowest sensor, although typically $H_{\text {inf }}$ decreases across the TAT platform, but increases across the LST platform (discussed later). Furthermore, unlike at LST where the largest values of $H_{\text {inf }}$ tend to coincide with the most energetic offshore forcing, $H_{\text {inf }}$ at TAT shows little response to offshore forcing.

To investigate the infragravity wave energy level over the complete field survey period and its relationship with the offshore wave forcing at both sites, Fig. 4 shows $H_{\text {inf }}$ parameterized by the forcing parameter $H_{o}^{2} T_{p}$ (following Inch et al., 2017), where $H_{o}$ is the offshore wave height. The parameter $H_{o}^{2} T_{p}$ is used as it is proportional to the offshore wave energy flux. To have a consistent value representing $H_{\text {inf }}$ with which to relate to the offshore forcing conditions, $H_{\text {inf }}$ is averaged over the surf zone (i.e., $0<x / x_{b}<1$ ) for each burst. To obtain values of $H_{o}, H_{S S}$ at the seaward-most sensor at LST during high tide conditions and the ADCP at TAT is deshoaled to a representative offshore water depth $(20 \mathrm{~m})$ using linear wave the- 

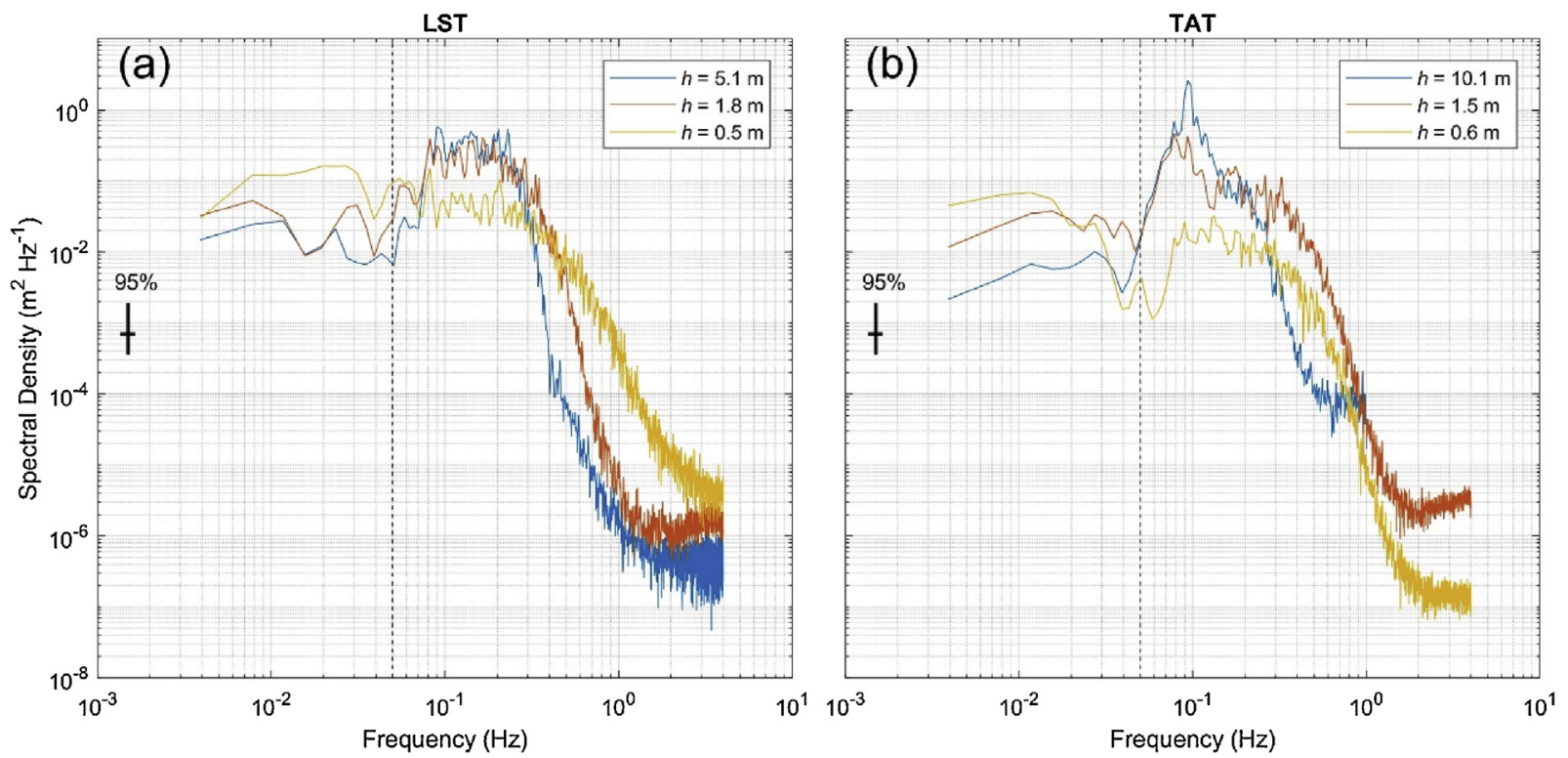

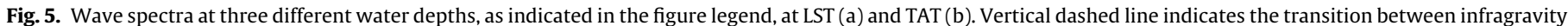
and sea-swell frequencies at $0.05 \mathrm{~Hz}$. A 95\% confidence bar is given in the figure.

Table 2

Offshore wave conditions during two example data bursts at LST and TAT.

\begin{tabular}{llll}
\hline & $\boldsymbol{H}_{\boldsymbol{o}}(\mathrm{m})$ & $\boldsymbol{T}_{\boldsymbol{p}}(\mathrm{s})$ & $\boldsymbol{H}_{\boldsymbol{o}}^{2} \boldsymbol{T}_{\boldsymbol{p}}\left(\mathrm{m}^{2} \mathrm{~s}^{-1}\right)$ \\
\hline LST & 0.81 & 11.1 & 7.30 \\
TAT & 0.90 & 10.7 & 8.59 \\
\hline
\end{tabular}

ory (ignoring wave refraction). Furthermore, data from LST are only included for bursts where $h>3 H_{s s}$ at the seaward-most sensor to ensure that the data are well outside the surf zone when deshoaled.

Data from LST show that $H_{\text {inf }}$ is well predicted by $H_{o}^{2} T_{p}$, with a linear regression revealing a coefficient of determination $r^{2}$ of 0.79 (Fig. 4). There is no evidence of infragravity saturation at LST as $H_{\text {inf }}$ progressively increases with increasing $H_{o}^{2} T_{p}$. These results are consistent with the findings of Inch et al. (2017) using data from a dissipative sandy beach, and other sandy beach studies that have indicated the importance of wave period in parameterizing infragravity energy in the nearshore (e.g., Ruessink, 1998; Senechal et al., 2011; Contardo and Symonds, 2013). In contrast, $H_{\text {inf }}$ at TAT shows a very weak and barely significant relationship with $H_{o}^{2} T_{p}$ (Fig. 4). The maximum $H_{o}^{2} T_{p}$ value at TAT exceeds that of LST; yet, the corresponding $H_{\text {inf }}$ is over $50 \%$ smaller at $0.11 \mathrm{~m}$ compared to $0.26 \mathrm{~m}$ at LST. There is also a strong indication that the infragravity wave motion at TAT is saturated for $H_{o}^{2} T_{p}>10$.

\subsection{Infragravity generation and propagation}

To investigate the generation and propagation of infragravity waves on the two contrasting platforms in detail, two example data bursts were selected for further analysis. The bursts that were selected have a similar level of offshore forcing (Table 2) and a good range of water depths throughout the surf zone.

Fig. 5 shows the wave spectra at three different water depths on each platform, including the seaward-most sensor at LST and the ADCP at TAT, for the two data bursts. The sea-swell variance at LST is quite broad-banded and there is a slight decrease between $h=5.1 \mathrm{~m}\left(x / x_{b}=1.83\right)$ and $h=1.8 \mathrm{~m}\left(x / x_{b}=0.65\right)$, before becoming significantly less at $h=0.5 \mathrm{~m}\left(x / x_{b}=0.19\right)$ (Fig. $\left.5 \mathbf{a}\right)$. The infragravity variance displays the reverse of this trend, with a small increase between the two deepest sensors and a large increase to the shallowest sensor. The sea-swell variance at TAT is more narrow-banded at the ADCP location where $h=10.1 \mathrm{~m}$ $\left(x / x_{b}=1.77\right)$, but decreases and becomes less narrow-banded in shallower waters on the platform (Fig. $5 \mathbf{b}$ ). The infragravity variance increases significantly between the ADCP and the platform at $h=1.5 \mathrm{~m}\left(x / x_{b}=0.55\right)$, and then increases further at low infragravity frequencies $(<0.02 \mathrm{~Hz})$, but decreases at high infragravity frequencies $(>0.02 \mathrm{~Hz})$ at $h=0.6 \mathrm{~m}\left(x / x_{b}=0.19\right)$.

Time series of the incident waves, wave groups and infragravity waves for different locations across the shore platforms for the two data bursts are illustrated in Fig. $6 \mathbf{a}$ and b. Compared to the seaward-most sensors at LST, waves at the ADCP at TAT are narrowbanded, clearly grouped, and fewer in number. Individual wave groups at LST can be traced through the shoaling zone into the outer surf zone before becoming indistinguishable. At TAT, while the wave groups are clear at the ADCP, the groupiness is much less defined on the platform. The increasing importance of infragravity waves in shallow water is quite clear at LST, but less so at TAT. Incident-wave statistics are shown in Fig. $6 \mathbf{c}$ and demonstrate that $H_{s S}$ at TAT decreases very rapidly in the outer surf zone close to the platform edge, before decreasing steadily in the inner surf zone. In contrast, the dissipation of $H_{s S}$ at LST is more rapid through the surf zone. As alluded to earlier, $H_{\text {inf }}$ increases shoreward on the LST platform, but decreases on the TAT platform, until the very inner surf zone where it increases (Fig. 6d). Infragravity energy becomes increasingly important relative to sea-swell energy in shallower water on both platforms, accounting for $\sim 25 \%$ of the total variance at the shoreward-most sensors (Fig. 6e).

Cross-correlation analysis was used to explore the infragravity wave generation mechanism for the two data bursts at LST and TAT shown in Fig. 6. The cross-correlation between the wave group envelope at the seaward-most sensors (PT15 at LST and the ADCP at TAT) and the infragravity signal at all locations, and between the wave group envelope and infragravity signal locally are both shown in Fig. 7.

At the seaward-most sensor on the LST platform, $r_{0}$ is significantly less than 0 indicating the presence of a bound infragravity wave that is $180^{\circ}$ out of phase with the wave groups. However, the strongest negative correlation does not occur at zero time lag, but at a lag of $1.8 \mathrm{~s}$, thus implying that the trough of the bound infragrav- 

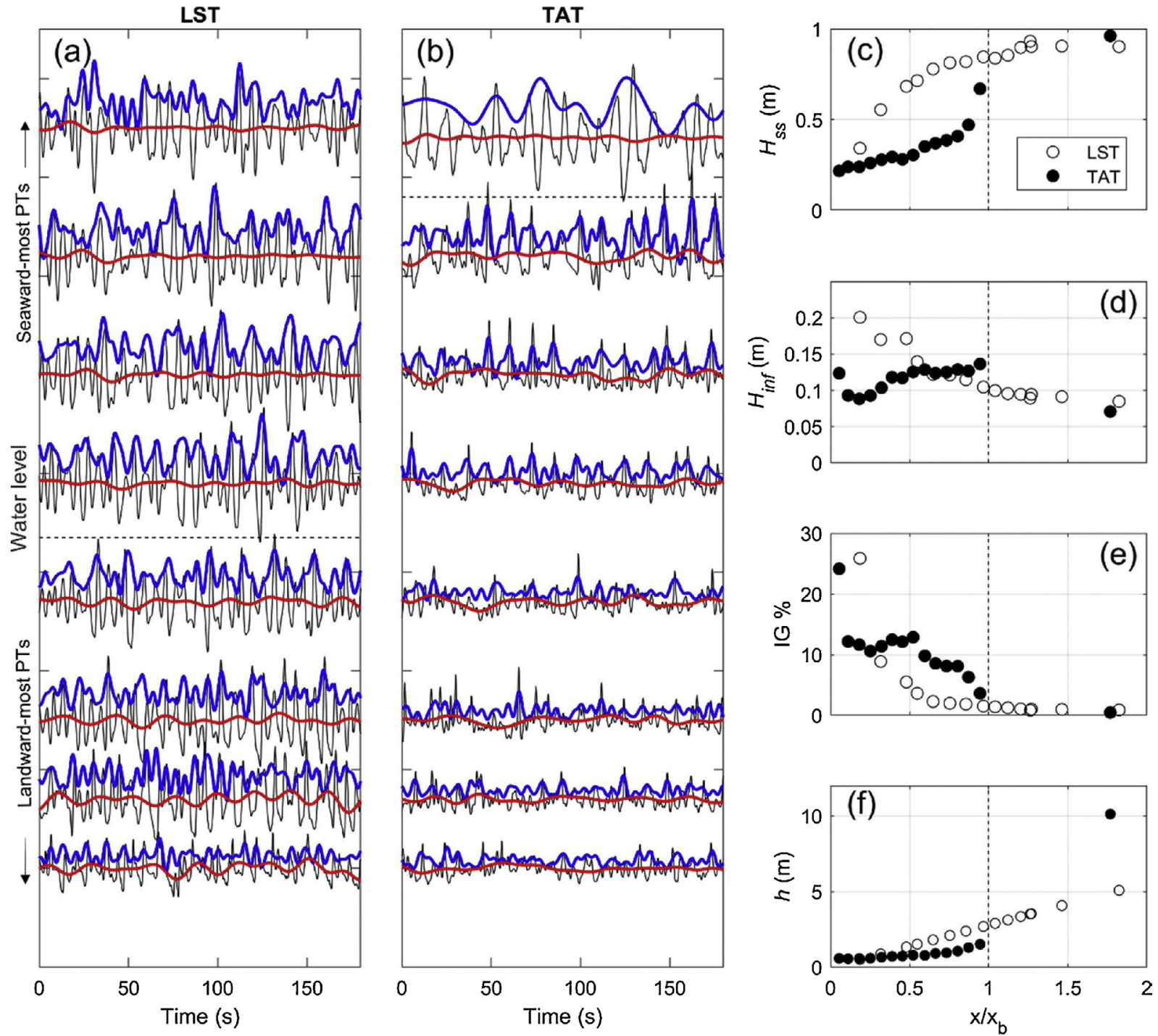

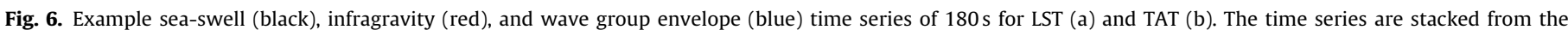

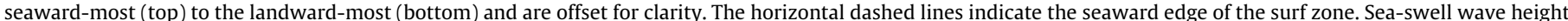

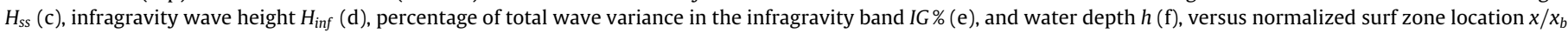
at LST (circles) and TAT (dots). Vertical dashed lines indicate the sea-swell wave breakpoint at $x / x_{b}=1$.

ity wave lags behind the crest of the wave group envelope. As the bound infragravity wave propagates shoreward towards the seaswell wave breakpoint, this lag grows to almost $5 \mathrm{~s}$, as evidenced by the increased deviation away from the predicted lag according to the wave group celerity $C_{g}$ (Fig. 7a). The lag does not appear to increase further in the surf zone where the bound wave continues to propagate shoreward according to $C_{g}$, but the correlation weakens significantly in the inner half of the surf zone $\left(x / x_{b}<0.5\right)$. The local cross-correlation between $A$ and $\eta_{\text {inf }}$ at LST (Fig. 7b) remains negative at zero time lag from the seaward-most sensor all the way to the very inner surf zone where there is some evidence of a switch from negative to positive correlation very close to shore.

At TAT, there is also clear evidence of a bound infragravity wave at the ADCP location, as shown by the bar of strong negative (blue) correlation (Fig. 7c). Similar to LST, the strongest negative correlation occurs at a non-zero time lag of $4 \mathrm{~s}$. Due to the lack of sensors on the platform edge, where sea-swell wave breaking occurs, as well as uncertainties regarding the exact bed profile shape between the $\mathrm{ADCP}$ and the seaward extent of the measured profile, calculation of the predicted lag was not attempted; therefore, the fate of the bound infragravity wave on reaching the platform cannot be determined using the field data alone and is investigated using numerical modelling later in the paper. However, in contrast to on the LST platform, the local cross-correlation between $A$ and $\eta_{\text {inf }}$ at TAT is positive at all locations on the platform, indicating that the infragravity wave and the wave group are in phase. This switch from negative to positive correlation suggests that the infragravity wave motion on the platform is generated using the breakpoint-forced mechanism, operating at the platform edge.

To assess whether the results from the two example data bursts presented in Fig. 7 are representative for the two entire datasets, Fig. $8 \mathrm{a}$ and $\mathrm{b}$ shows the local cross-correlation coefficient at zero time lag for all locations and all bursts, relative to the normalized surf zone position. At LST, $r_{0}$ is almost entirely negative outside of the surf zone indicating that bound infragravity waves are dominant. The negative correlation increases towards the sea-swell wave breaking point and decreases across the surf zone. This can be interpreted as the bound infragravity waves being released as the sea-swell waves break and lose their group structure. Correlation becomes positive in the inner third of the surf zone, thus supporting 


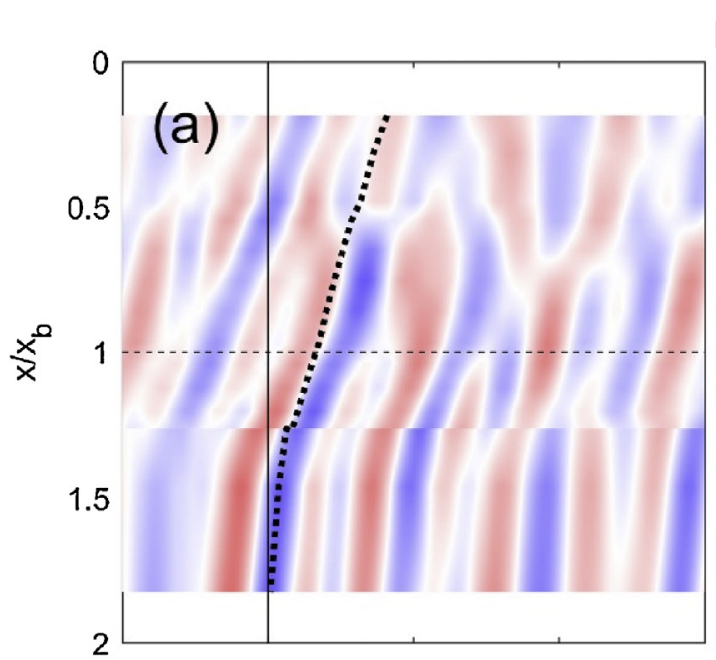

LST

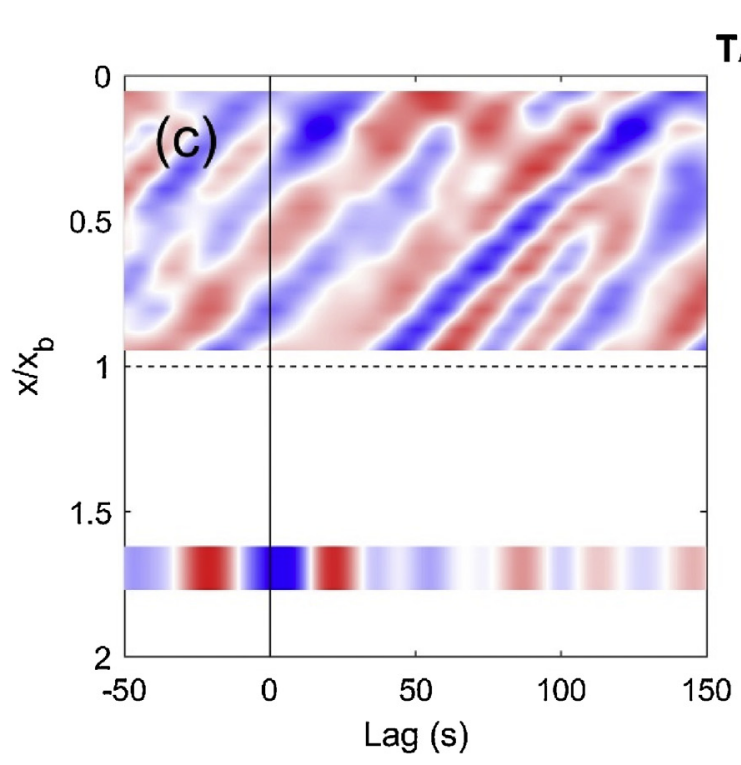

TAT
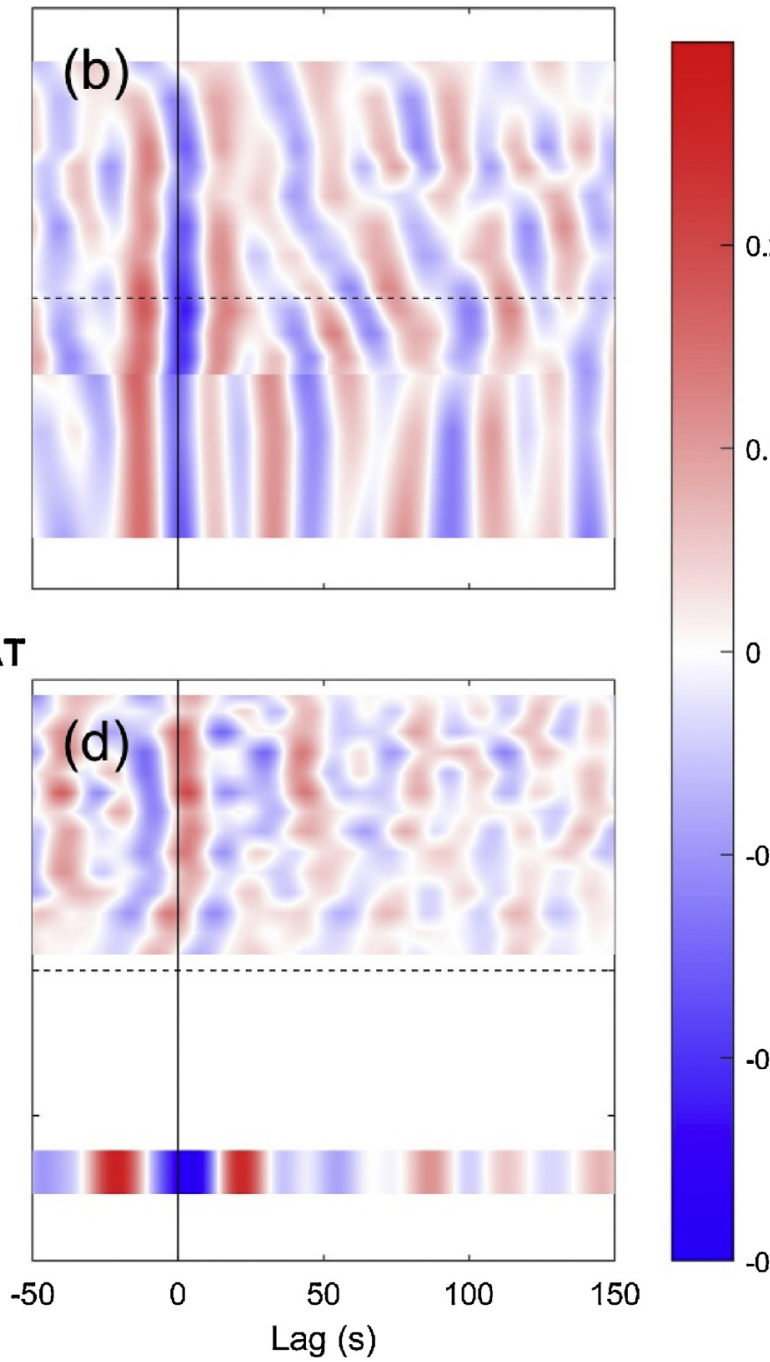

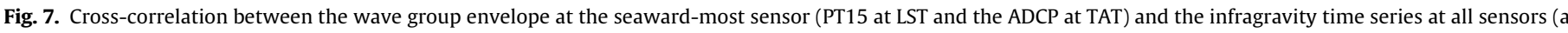

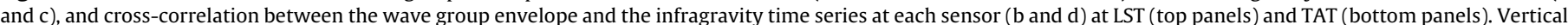

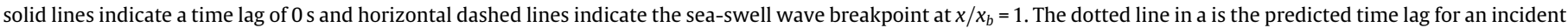
wave propagating at the wave group celerity $C_{g}$. Red indicates positive correlations and blue indicates negative correlations.

the previous assertion that the correlation in Fig. 7b looked likely to switch from negative to positive close to shore. The relationship between bound infragravity waves and the sea-swell wave group is further elucidated by the corresponding groupiness factors presented in Fig. 8c. The groupiness decreases in the outer surf zone following initial sea-swell wave breaking, and coinciding with the release of the bound infragravity waves, before rising rapidly in the inner surf zone to correspond with the switch to positive $r_{0}$.

The TAT data show that bound infragravity waves are prevalent at the ADCP, as indicated by the predominantly negative $r_{0}$ at this location. However, on the platform $r_{0}$ is mostly positive at all locations, as was also apparent in Fig. $7 \mathrm{~d}$. This provides further evidence that breakpoint-forced infragravity waves are dominant on the TAT platform as they are in phase with the sea-swell wave groups. The groupiness of the sea-swell waves at TAT increases significantly between the ADCP and the platform (Fig. 8d), perhaps as a result of strong shoaling on the platform slope. Unlike at LST, the groupiness decreases and is lowest in the inner surf zone. This is likely associated with the rapid dissipation of the sea-swell waves in the outer surf zone shortly after they have propagated onto the platform, as was shown in Fig. 6c.

\subsection{XBeach modelling}

The field results presented thus far have provided strong evidence that bound infragravity waves are dominant on the LST platform and, with slightly more reservations, that breakpointforced infragravity waves dominate the platform at TAT. To investigate this further, the non-hydrostatic (i.e., phase-resolving) version of the XBeach numerical model (Roelvink et al., 2009) was used.

The two example data bursts of field data shown in Figs. 5-7 were used to help validate the XBeach model. It is emphasised that we do not seek to provide an extensive calibration of the numerical model as at both sites we do not have the appropriate wave boundary conditions to force the model, nor do we have the complete bathymetry at the TAT site. Rather, the comparison, presented in Fig. 9, serves to demonstrate qualitative agreement between the field data and model results. The numerical model reproduces the observed shoreward decrease in $H_{s s}$ across the shore platform quite well at both LST and TAT (Fig. 9c and g). Qualitatively, there is also good agreement between modelled and observed $H_{\text {inf }}$; however, quantitatively the agreement is not great: $H_{\text {inf }}$ is over-predicted by 

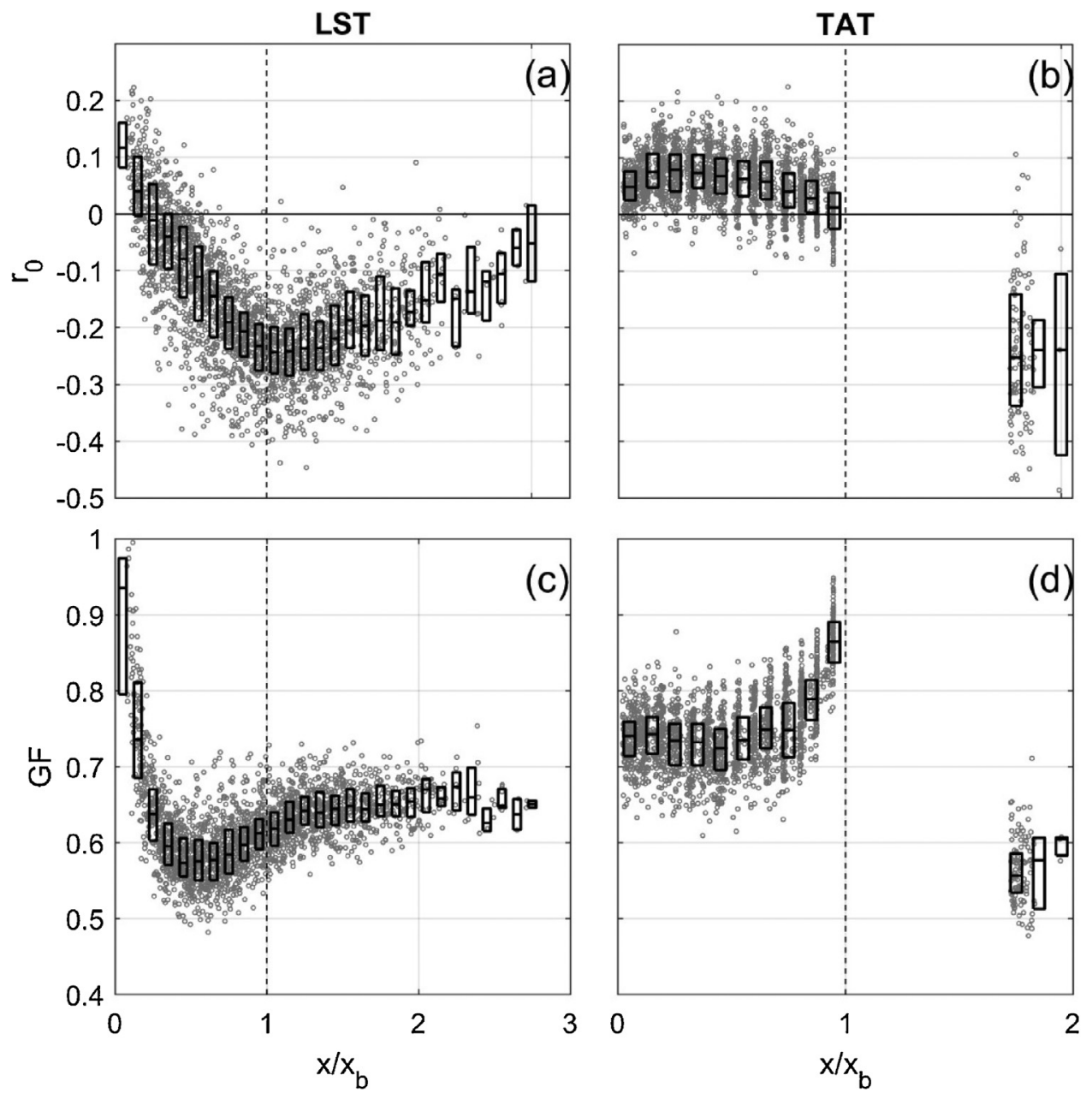

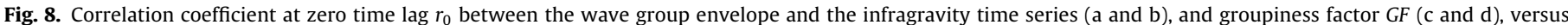

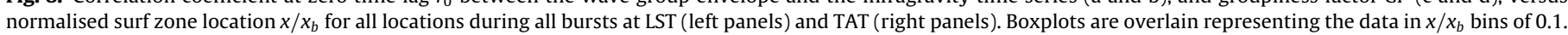
On each box, the central line is the median value and the upper and lower bounds are the $75^{\text {th }}$ and $25^{\text {th }}$ percentiles, respectively.

around $0.07-0.10 \mathrm{~m}$ for LST (Fig. 9d) and by $0.03-0.05 \mathrm{~m}$ for TAT (Fig. 9h).

The modelled cross-correlation between the wave group envelope at the most seaward coordinate and the infragravity time series at all locations for LST (Fig. 9a) closely mimics what was seen in the field data (Fig. 7a). As was observed in the field data, the lag associated with the strong band of negative (blue) correlation increases relative to the predicted lag as it approaches the surf zone, reaching $\sim 7 \mathrm{~s}$ at the outer edge of the surf zone. This suggests that the trough of the bound wave lags behind the crest of the wave group by an amount that increases as the sea-swell waves shoal prior to breaking. The local cross-correlation between $A$ and $\eta_{\text {inf }}$ (Fig. 9b) also matches the field results (Fig. 7b) very well, remaining negative at zero time lag throughout the model domain up until the very inner surf zone where it turns to positive (Fig. 9b). This occurs because the infragravity wave crests increase the local water depth allowing for larger sea-swell waves to exist whilst the smaller sea-swell waves propagate in the infragravity wave troughs.

The modelled cross-correlation between the wave group envelope at the most seaward coordinate and the infragravity time series at all locations for TAT is similar to LST outside the surf zone, where a band of negative correlation indicates the presence of a bound infragravity wave (Fig. 9e). This was also observed in the field data (Fig. 7c). Also, like in the model run for LST, the bound infragravity wave lags increasingly behind the predicted lag according to $C_{g}$, up to $\sim 7 \mathrm{~s}$ at the platform edge. However, on reaching the shore platform, the band of negative correlation associated with the bound infragravity wave rapidly weakens, whilst a band of positive (red) correlation suddenly emerges in front of the wave group and propagates towards the shore, by which time the bound infragravity waves has all but disappeared (Fig. 9e). As with the field data from the TAT platform (Fig. 7d), the local cross-correlation at zero time lag sees a rapid switch from negative to positive at the platform edge (Fig. 9f), supporting the loss of the bound wave and introduction of a breakpoint-forced infragravity wave. The outgoing infragravity wave, originating at the sea-swell wave breakpoint is also characteristic of the breakpoint-forced mechanism.

Before presenting all model results across the full parameter space $\left(H_{o}=1-4 \mathrm{~m} ; T_{p}=6-14 \mathrm{~s}\right)$ in the next section, Fig. 10 shows the model output for an idealised sloping and horizontal platform, for $H_{o}=4 \mathrm{~m}$ and $T_{p}=12 \mathrm{~s}$. An identical wave signal was used in these two simulations and a snapshot of the wave profiles across the topography, as well as the cross-shore variation in mean sea level and significant wave height, are plotted in the upper panel of Fig. 10. For both platforms there is a residual wave height at the base of the cliff. The two middle pairs of panels shows the incoming and outgoing infragravity wave signal, derived using a lowpass filter of $T_{p} / 4$ and the method of Guza et al. (1984), and the lower pair of panels shows the cross-shore variation in the total, incoming and outgoing significant infragravity wave height $H_{s, i n f}$. For the sloping platform (left panels) the incoming infragravity signal (assumed to be the 

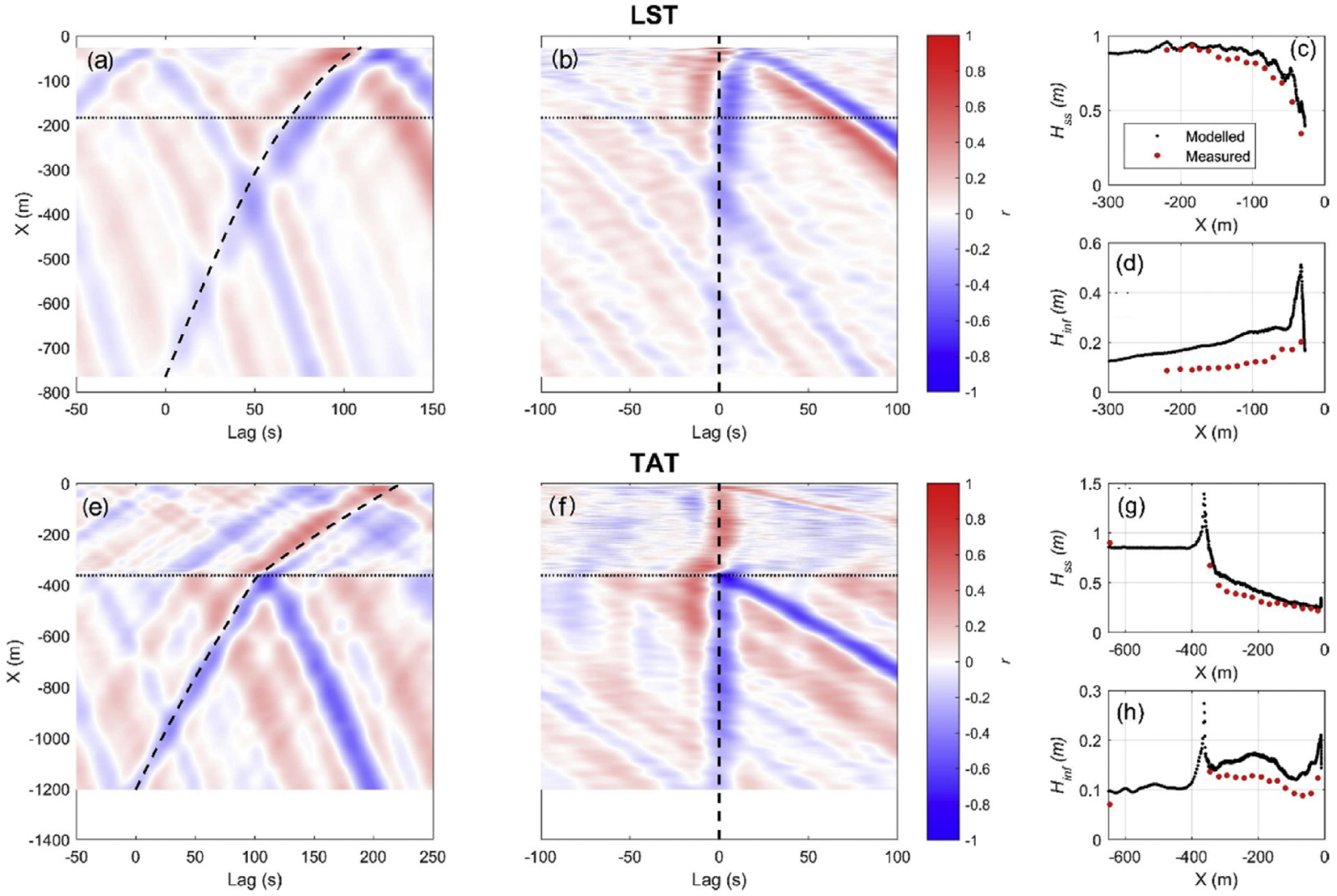

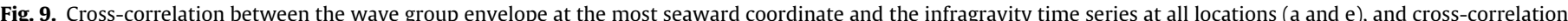

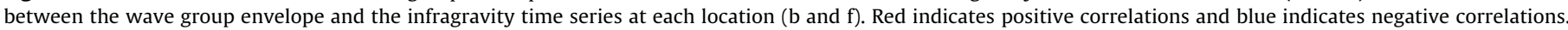

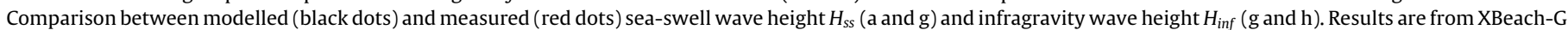
model runs simulating LST (top panels) and TAT (bottom panels) using the same forcing conditions as in Fig. 7. Note the different axis limits.

bound long wave based on previous results) progressively increases in amplitude towards the shore. Part of the incoming signal reflects at the cliff, generating a less energetic outgoing infragravity signal. The infragravity motion on the horizontal platform is more complex. There is still an incoming bound long wave signal, but, at the submerged platform edge, the infragravity crests become troughs on the platform, and the troughs become crests. As demonstrated earlier, this is the indicative of the time-varying breakpoint mechanism of infragravity wave generation. There are also two outgoing infragravity wave signals: one originating at the submerged platform edge (outgoing time-varying breakpoint wave) and one at the cliff at the landwards limit of the platform (reflection of the incoming time-varying breakpoint wave). The infragravity wave motion at the base of the cliff on the sub-horizontal platform $\left(H_{s, i n f}\right.$ $=1.5 \mathrm{~m})$ is more energetic than that on the sloping platform $\left(H_{s, \text { inf }}\right.$ $=1.2 \mathrm{~m}$ ). The reduction in $H_{s, i n f}$ at $x=100 \mathrm{~m}$ on the sloping platform and $x=150 \mathrm{~m}$ on the sub-horizontal platform is due to standing infragravity wave motion.

\section{Discussion}

\subsection{Bound long wave versus breakpoint forcing}

The numerical modelling results agree very well with the field data and indicate that the infragravity waves on the sloping platform (LST) have characteristics akin to those observed on dissipative beaches (e.g., Ruessink, 1998; Janssen et al., 2003; Inch et al., 2017), whilst infragravity wave observations on the subhorizontal platform (TAT) agree well with those from steep beaches and coral reefs (e.g., Baldock, 2006; Lara et al., 2011; Pomeroy et al., 2012; Masselink et al., 2019). Furthermore, cross-correlation anal- ysis between the infragravity motion across the shore platform and the wave groupiness seaward of the surf zone provides strong evidence that infragravity waves on the sloping platform are related to bound long waves whereas those on the sub-horizontal platform are breakpoint-forced long-waves. The key distinguishing factor between the two mechanisms of infragravity wave generation is the gradient over which the incident waves shoal and break (e.g., Battjes et al., 2004), with a secondary role played by the incident wave steepness (e.g., Baldock and Huntley, 2002).

Baldock (2012) proposed a useful framework to enable an evaluation of the relative importance of the two mechanism through a surf beat similarity parameter $\xi_{\text {surfbeat }}$, which combines the normalised bed slope with the wave steepness as

$\xi_{\text {surfbeat }}=\beta_{\text {norm }} \sqrt{\frac{H_{b}}{L_{o}}}$

where $L_{0}$ is the short-wave deep-water wave length, $H_{b}$ is the wave height at the sea-well wave breakpoint and $\beta_{\text {norm }}$ is the normalised bed slope as proposed by Battjes et al. (2004) as

$\beta_{\text {norm }}=\frac{h_{x}}{\omega_{\text {low }}} \sqrt{\frac{g}{h_{b}}}$

where $h_{x}$ and $h_{b}$ are the beach slope and the depth at breaking, respectively, $\omega_{\text {low }}$ is the radian long-wave frequency, and $g$ is the gravitational acceleration. Small and large values of $\xi_{\text {surfbeat }}$ favour the BLW and BFLW mechanism, respectively, with a $\xi_{\text {surfbeat }}$ value of 0.05-0.1 separating the two IG wave regimes (cf. Baldock, 2012, his Table 1; Contardo and Symonds, 2013, their Table 2). 

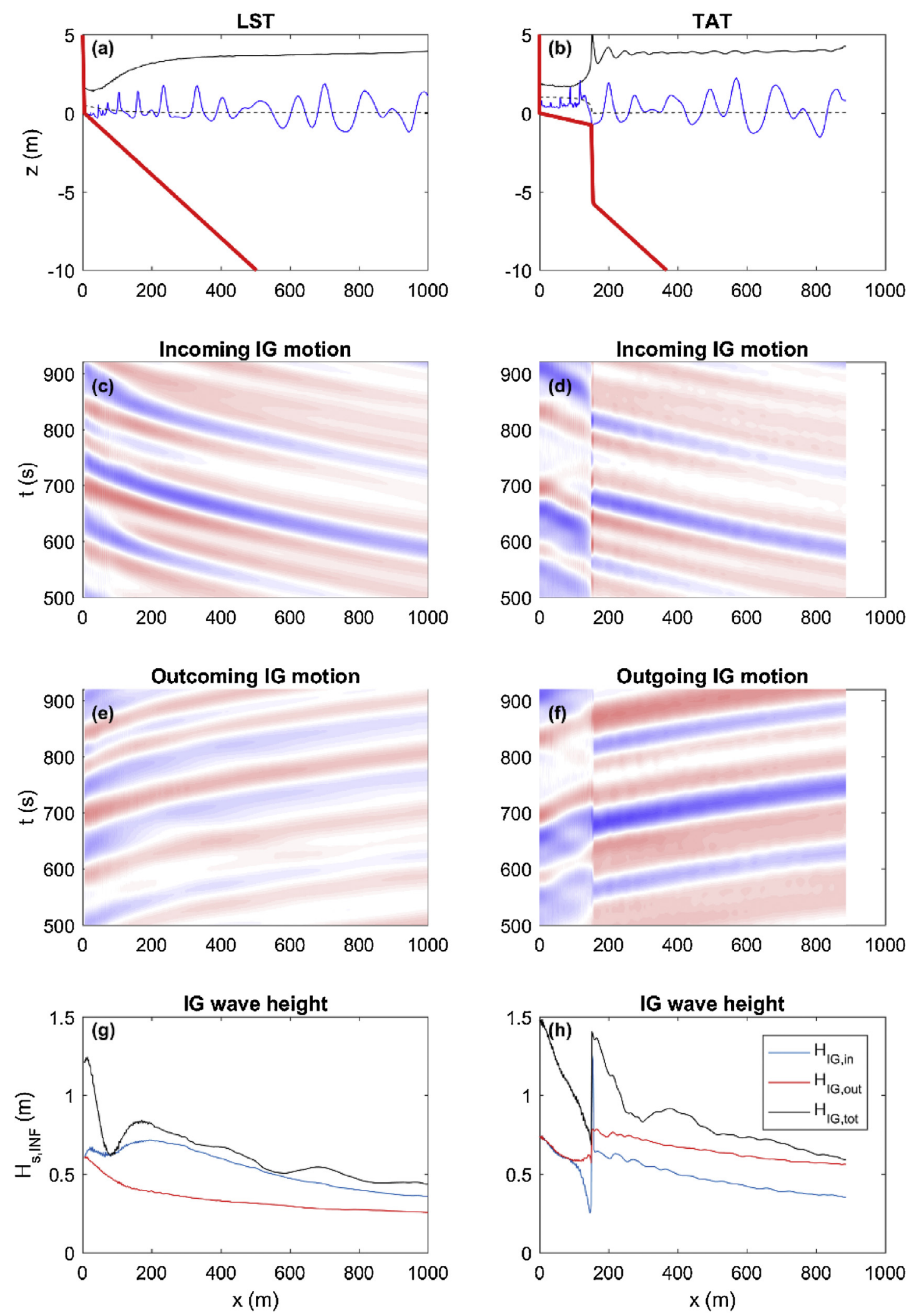

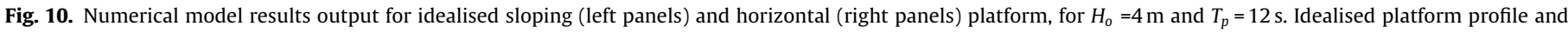

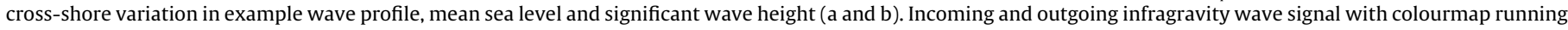
from $-0.7 \mathrm{~m}$ (blue) to $+0.7 \mathrm{~m}$ (red), (c, d, e and f). Total, incoming and outgoing significant infragravity wave height $H_{s, \text { inf }}$, (g and h).

Inserting Eq. (6) into Eq. (7) yields

$\xi_{\text {surfbeat }}=(1 / \sqrt{2 \pi})\left(T_{I G} / T_{p}\right) \sqrt{\gamma} h_{x}$ where $T_{I G}$ and $T_{p}$ are the infragravity and incident wave period, respectively, and $\gamma$ is the breaker criterion $H_{b} / h_{b}$. Assuming a typical IG-wave period $T_{I G}$ of 4 times the incident-wave period $T_{p}$ and an 
irregular breaker criterion of $H_{b} / h_{b}=0.5$, Eq. (8) reduces to $\xi_{\text {surfbeat }}$ $\approx 1.13 h_{x}$, and $\xi_{\text {surfbeat }}$ is independent of the incident wave height or period. Finally, inserting a $\xi_{\text {surfbeat }}$ threshold of $0.05-0.1$ separating the two IG wave regimes, following Baldock (2012) and Contardo and Symonds (2013), results in a beach gradient threshold of 0.04-0.09. This implies that the bound long wave mechanism can be expected to dominate on most sloping platforms, whose platform gradient is always less than 0.1 and usually less than 0.05 (Trenhaile, 1999), whereas the breakpoint-forced mechanism is expected to dominate sub-horizontal platforms as these generally have a very steep low tide cliff and subtidal profile (Sunamura, 1992; Kennedy, 2015).

\subsection{Which mechanism is most effective at generating infragravity waves?}

Using data from the additional XBeach model runs with $H_{o}=1-4 \mathrm{~m}$ and $T_{p}=6-14 \mathrm{~s}$, Fig. 11 illustrates the relationship between $H_{s, \text { inf }}$ and $H_{o}^{2} T_{p}$ across this wide parameter space. The LST and TAT field data are included in the plot, as well as field data collected from Perranporth Beach, Cornwall, UK, from the study by Inch et al. (2017), to provide comparison with a dissipative sandy beach. During the Perranporth field experiment, $H_{0}$ ranged from 0.4 to $3.9 \mathrm{~m}$ and $T_{p}$ varied between 6 and $20 \mathrm{~s}$; thus, conditions significantly more energetic than experienced during the shore platform experiments. For all measured and modelled data sets, $H_{s, \text { inf }}$ is averaged over the zone $0<x / x_{b}<0.33$ (i.e., inner third of the surf zone), hence the notation $\left\langle H_{s, \text { inf }}>\right.$ is used.

The model results for both rock platform sites are comparable and indicate that $<H_{s, i n f}>$ increases rapidly for $H_{o}^{2} T_{p}<50 \mathrm{~m}^{2} \mathrm{~s}^{-1}$, before increasing at a slower rate beyond this level. This trend is replicated in the Perranporth field data, although the latter seem to plot somewhat below the platform model results (note, however, that these are field measurements and not model results). The field data from LST and TAT generally agree well with the model results; however, they cover a very small parameter space $\left(H_{o}^{2} T_{p}\right.$ $<230 \mathrm{~m}^{2} \mathrm{~s}^{-1}$ ) and additional data from both types of platforms under a greater range of forcing conditions is required to confirm the model results.

The relationship between $<H_{s, \text { inf }}>$ and $H_{o}^{2} T_{p}$ shown in Fig. 11 for both sites suggests that a linear parameterization of the infragravity wave height with the offshore forcing, as has often been applied in previous studies, may not be suitable. The present results agree with those of Senechal et al. (2011) who found that the best statistical predictor of infragravity runup on a dissipative beach with a steep foreshore slope is not a linear fit, but rather a hyperbolictangent function. Furthermore, a non-linear fit solves a common issue experienced when attempting to fit a linear line to infragravity wave height or runup in which the linear line intercepts the vertical axis at a value greater than 0 . This is counter-intuitive as it implies that there is some infragravity energy even when there is a complete absence of offshore forcing. The non-linear curves fitted to the model results for LST and TAT, and the linear fit for Perranporth, plotted in Fig. 11, describe the model data very well, with $\mathrm{r}^{2}$ of $0.85,0.79$ and 0.94 , respectively. It must be emphasised, however, that these equations are highly site-specific (mainly dependent on morphology and water level) and are not universally applicable.

The field observations at LST and TAT, and the supporting numerical model simulations, strongly suggest that the potential for infragravity wave generation for sloping platforms is similar to that for sub-horizontal platforms. This suggests that the bound long wave mechanism of infragravity wave generation is as efficient as the breakpoint-forced mechanism. This is in apparent contrast to the recent study of Masselink et al. (2019), who applied XBeach to model wave transformation across coral reef platforms and concluded that the breakpoint-forced mechanism is the more effective generator of infragravity energy, and that the most energetic infragravity wave motion (normalised by incident wave motion) is generated on reef platforms with a steep fore reef slope $>1 / 6$. There is, however, a fundamental difference between the topographic profiles of coral reef and shore platform settings. Horizontal platforms are similar to coral reefs with both characterised by a (sub)-horizontal platform fronted by a steep submerged cliff; however, a sloping platform represents a continuous gradient and does not have terminating (sub)-horizontal platform. Thus, in the continuously sloping platform case, any BLW is able to 'grow' as it propagates across the sloping platform, whereas in the case of a coral platform fronted by a low-gradient fore reef, the BLW is 'released' at the breakpoint near the seaward edge of the reef platform. It is also worth pointing out that the water depth at the base of fore reefs is generally much larger than at the base of the low tide cliff of sub-horizontal shore platforms. Therefore, the characteristics of the infragravity wave motion arriving at the different types of platforms are expected to be dissimilar. Clearly, some care has to be exercised when transferring the current findings across to different coastal settings as site-specific factors play a very significant role in the wave transformation and infragravity wave generation processes.

\subsection{Geomorphic implications}

This paper provides the first detailed comparison of the different ways in which sloping and sub-horizontal shore platforms filter the wave energy available for geomorphic work (erosion) at the cliff toe. A unified conceptual framework for the origin of rock platforms is not yet available: Trenhaile $(1987,1999)$ described the critical role of tidal range (sloping platforms occur mainly in larger tidal ranges and sub-horizontal platforms occur mainly in micro-tidal settings), whereas Sunamura (1992) distinguished both types in micro-tidal settings on the basis of incident wave force and rock resistance: larger waves/weaker rock result in erosion of the seaward edge of shore platforms and sloping platforms develop, whereas harder rocks/weaker incident waves preserve or partially preserve the seaward edge, forming sub-horizontal platforms. In the field, a clear demarcation between platform types is not always obvious and recent modelling has demonstrated that different platform types can develop across a very broad parameter space in which wave erosion and rock weathering processes variously dominate (e.g., Matsumoto et al., 2018).

Regardless of formative demarcation conditions and the relative importance of wave and weathering processes, our results highlight important differences in the wave regimes operating on each platform type. Comparison of wave transmission across sloping and sub-horizontal platforms, that are relatively similar in width and wave exposure, but different in terms of tidal range, platform slope and the presence/absence of a steep seaward edge, suggest that sub-horizontal platforms are more effective in filtering both incident and infragravity wave energy and should therefore be characterised by lower wave energy levels at the emerged cliff toe. Results further suggest contrasting mechanisms of infragravity wave generation on sloping and sub-horizontal platforms. Overall the results are generally consistent with conceptual models of shore platform development, but add important mechanistic understanding.

Recent reviews of rock platform development (Trenhaile, 2018, 2019) emphasise the importance of both wave erosion and weathering across the full spectrum of platforms. Under stable sea level conditions platforms attain states of static equilibrium, and hence stable profile morphology, due to wave erosion. During times of changing sea level, sloping shore platforms are thought to evolve in dynamic equilibrium through shore-parallel cliff retreat and maintain their general profile shape (e.g., Challinor, 1949; Trenhaile, 


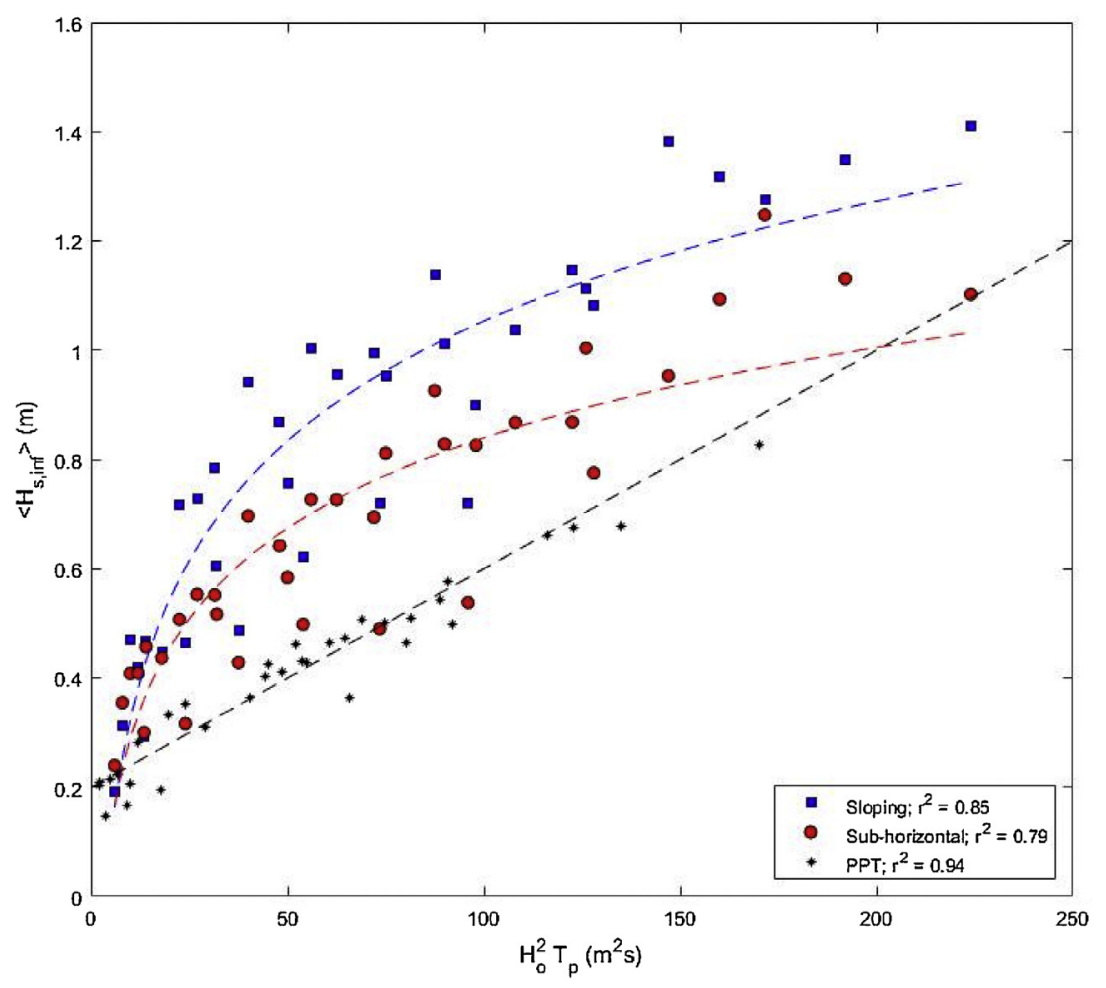

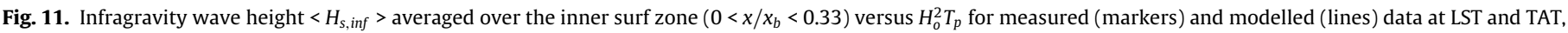
and measured data from Perranporth Beach (PPT), UK, from Inch et al. (2017).

1974; Walkden and Dickson, 2008). Our results in a macro-tidal setting confirm that rapid tidal translation exposes the entire surveyed width of the sloping platform surface to wave energy at incident frequencies, and that the bound long wave mechanism dominates infragravity wave energy generation on these surfaces, providing a mechanism for elevating water levels at the cliff toe. Whilst this elevates the zone of maximum wave energy expenditure upwards and further landwards, which increases the mechanical impact of short-period waves, enhances debris removal and enlarges the spatial extent of the wetting and drying that leads to weathering, rock resistance also remains important in setting the height of the cliff toe (cf. Trenhaile 2018). In contrast, sub-horizontal platforms are thought to have declining rates of cliff recession through time (e.g., Sunamura, 1992), because platform gradients are reduced to a level where wave generated shear stresses are below the erosional threshold. Continued cliff recession becomes possible only through rock degradation accomplished by subaerial weathering processes and debris removal by infragravity wave energy (Dickson et al., 2013). Our results confirm other studies that show that subhorizontal platforms are effective in filtering incident energy (e.g., Marshall and Stephenson, 2011; Ogawa et al., 2011), and explain that the breakpoint-forced mechanism is the likely source of infragravity wave energy on such platforms. As described above, the key distinguishing factor between the two mechanisms of infragravity wave generation is the gradient over which the incident waves shoal and break. Following Baldock (2012) and Contardo and Symonds (2013), the threshold gradient is likely to be in the range 0.04 to 0.09 . Therefore the breakpoint-forced mechanism must clearly be the dominant source of infragravity wave energy on shore platforms where a steep seaward edge (low-tide cliff) has been preserved as a near-vertical cliff (e.g., Dickson, 2006). This paper shows that on sub-horizontal platforms with partially preserved steep seaward edges developed in softer rocks such as the silt- and sandstone at TAT the dominant mechanism of infragravity wave generation remains breakpoint forcing.
It is interesting to contemplate that future sea-level rise may change the wave regime on sub-horizontal shore platforms. While the relative elevation of the platform edge compared to the tidal elevation remains important, as water levels rise, wave breaking may be less constrained to the seaward edge and shift to parts of the shore platform that slope more gently. Hence, increased water depth will not only increase the proportion of energy at incident and infragravity wave frequencies that reaches the cliff toe (because less energy will be expended on the platform edge), but it is also likely to switch the dominant mode of infragravity wave generation to the bound long wave mechanism.

\section{Conclusion}

This paper set out to investigate and compare the generation and transformation of infragravity waves on contrasting sloping and sub-horizontal shore platforms. Using field data from a sloping platform at Lilstock, UK, and a sub-horizontal platform at Leigh, New Zealand, complimented by numerical modelling (XBeach model), we have assessed the relative importance of the bound wave and the time-varying breakpoint theories of infragravity wave generation. Field measurements of wave transformation were collected over $8 / 6$ tides, tide range of $10.7 / 1.4 \mathrm{~m}$ and peak $H_{0}=1.91 / 1.57 \mathrm{~m}$ using 15/14 platform mounted pressure sensors, for sloping/subhorizontal platforms respectively.

The numerical modelling results strongly support the field data and indicate that infragravity waves on sloping platforms have characteristics similar to those on dissipative beaches, whereas infragravity wave observations on sub-horizontal platforms, align more closely with steep beaches and coral reefs. Further crosscorrelation analysis, between the infragravity motion across the shore platform and the wave groupiness seaward of the surf zone, shows that the group bound long wave mechanism is most important on sloping platforms, whereas breakpoint-forced long waves dominate on sub-horizontal platforms. 
Further investigation shows the transformation of infragravity energy across the platforms is somewhat more energetic on sloping platforms than that on sub-horizontal platforms. This supports suggestions that sub-horizontal platforms provide better protection to coastal cliffs than their more steeply sloping counterparts. The model results support comparable studies from dissipative beaches that suggest a linear parameterization of the infragravity wave height with the offshore forcing, as has often been applied in previous studies, may not be suitable. The authors acknowledge that site-specific geomorphic factors including the elevation of the seaward terminus of the platform and the gradient are likely to play a key role in wave transformation. Further studies, where possible, should focus on in-situ field measurements to capture extreme wave conditions $\left(H_{s}>5 \mathrm{~m}\right)$ that can then be support further numerical simulations.

\section{Acknowledgements}

This research was funded by EPSRC grantEP/L02523X/1, Waves Across Shore Platforms, awarded to GM and MJA. We would like to thank our field and technical team: Peter Ganderton, Tim Scott, Olivier Burvingt, Pedro Almeida and Kate Adams. The data on which this paper is based are available from TP or via the online repository found at http://hdl.handle.net/10026.1/9105.

\section{References}

Baldock, T.E., 2006. Long wave generation by the shoaling and breaking of transient wave groups on a beach. Proceedings of the Royal Society of London A 462 , 1853-1876.

Baldock, T.E., 2012. Dissipation of incident forced long waves in the surf zone implications for the concept of "bound" wave release at short wave breaking. Coast. Eng. 60, 276-285.

Baldock, T.E., Huntley, D.A., 2002. Long-wave forcing by the breaking of random gravity waves on a beach. Proceedings of the Royal Society of London A 458, 2177-2201.

Battjes, J.A., Bakkenes, H.J., Janssen, T.T., van Dongeren, A.R., 2004. Shoaling of subharmonic gravity waves. J. Geophys. Res. 109, C02009.

Becker, J.M., Merrifield, M.A., Yoon, H., 2016. Infragravity waves on fringing reefs in the tropical Pacific: dynamic setup. J. Geophys. Res. 121, 3010-3028.

Beetham, E.P., Kench, P.S., 2011. Field observations of infragravity waves and their behaviour on rock shore platforms. Earth Surf. Process. Landf. 36, 1872-1888.

Bertin, X., et al., 2018. Infragravity waves: from driving mechanisms to impacts. Earth. Rev. 177, 774-799.

Brander, R.W., Kench, P.S., Hart, D., 2004. Spatial and temporal variations in wave characteristics across a reef platform, Warraber Island, Torres Strait, Australia. Mar. Geol. 207, 169-184.

Cheriton, O.M., Storlazzi, C.D., Rosenberger, K.J., 2016. Observations of wave transformation over a fringing coral reef and the importance of low-frequency waves and offshore water levels to runup, overwash, and coastal flooding. J. Geophys. Res. 121, 3121-3140

Contardo, S., Symonds, G., 2013. Infragravity response to variable wave forcing in the nearshore. J. Geophys. Res. 118, 7095-7106.

Dickson, M.E., 2006. Shore platform development around Lord Howe Island, southwest pacific. Geomorphology 76 (3), 295-315

Dickson, M.E., Ogawa, H., Kench, P.S., Hutchinson, A., 2013. Sea-cliff retreat and shore platform widening: steady-state equilibrium? Earth Surf. Process. Landf. 38, 1046-1048

Farrell, E.J., Granja, H., Cappietti, L., Ellis, J.T., Li, B., Sherman, D.J., 2009. Wave transformation across a rock platform, Belinho, Portugal. J Coast. Res. SI 56, 44-48.

Garrett, C.J.R., Toulany, B., 1981. Variability of the flow through the Strait of Belle Isle. J. Mar. Res. 39, 163-189

Guza, R.T., Thornton, E.B., Holman, R.A., 1984. Swash on steep and shallow beaches. In: Proceedings of the 19th Conference on Coastal Engineering, ASCE, New York.

Hasselmann, K., 1962. On the non-linear energy transfer in a gravity-wave spectrum: part 1. General theory. J. Fluid Mech. 12, 481-500.

Inch, K., Davidson, M., Masselink, G., Russell, P., 2017. Observations of nearshore infragravity wave dynamics under high energy swell and wind-wave conditions. Cont. Shelf Res. 138, 19-31.

Jager, T., 2016. Infra-Gravity Wave Transformation Across Macrotidal Rocky Shore Platforms. Unpublished MSc Thesis. Technical University Delft, The Netherlands.

Janssen, T.T., Battjes, J.A., Van Dongeren, A.R., 2003. Long waves induced by shortwave groups over a sloping bottom. J. Geophys. Res. 108, 3252.

Jenkins, G.M., Watts, D.G., 1968. Spectral Analysis and Its Applications. Holden-Day, San Francisco.

Kennedy, D.M., 2015. Where is the seaward edge? A review and definition of shore platform morphology. Earth. Rev. 147, 99-108.
Kennedy, David M., 2016. The subtidal morphology of microtidal shore platforms and its implication for wave dynamics on rocky coasts. Geomorphology 268, 146-158.

Lara, J.L., Ruju, A., Losada, I.J., 2011. Reynolds averaged Navier-Stokes modelling of long waves induced by a transient wave group on a beach. Proceedings of the Royal Society of London A 467, 1215-1242.

List, J.H., 1991. Wave groupiness variations in the nearshore. Coast. Eng. 15, 475-496. Longuet-Higgins, M.S., Stewart, R.W., 1962. Radiation stress and mass transport in gravity waves with applications to 'surf beats'. J. Fluid Mech. 13, 481-504.

Lugo-Fernandez, A., Roberts, H.H., Wiseman Jr., W.J., Carter, B.L., 1998. Water level and currents of tidal and infragravity periods at Tague Reef, St. Croix (USVI). Coral Reefs 17, 343-349.

Marshall, R.J.E., Stephenson, W.J., 2011. The morphodynamics of shore platforms in a micro-tidal setting: interactions between waves and morphology. Mar. Geol. $288,18-31$.

Masselink, G., 1995. Group bound long waves as a source of infragravity energy in the surf zone. Cont. Shelf Res. 15, 1525-1547.

Masselink, G., Tuck, M., McCall, R., van Dongeren, A., Ford, M., Kench, P., 2019. Physical and numerical modelling of infragravity wave generation and transformation on coral reef platforms. Journal of Geophysical Research (Oceans) 124, 1410-1433 https://doi.org/10.1029/2018JC014411.

Matsumoto, H., Dickson, M.E., Kench, P.S., 2018. Modelling the relative dominance of wave erosion and weathering processes in shore platform development in micro- to mega-tidal settings. Earth Surf. Process. Landf. 43, 2642-2653.

McCall, R., Masselink, G., Austin, M., Poate, T., Jager, T., 2017. Modelling incidentband and infragravity wave dynamics on rocky shore platforms. In: Proceedings Coastal Dynamics, ASCE, Helsingor, Denmark, pp. 1658-1669.

Nutall, A.H., 1971. Spectral Estimation by Means of Overlapped FFT Processing of Windowed Data , Naval Underwater Systems Center (NUSC) Report No. 4169. New London, Connecticut.

Ogawa, H., Dickson, M.E., Kench, P.S., 2011. Wave transformation on a sub-horizontal shore platform, Tatapouri, North Island, New Zealand. Cont. Shelf Res. 31, 1409-1419.

Ogawa, H., Dickson, M.E., Kench, P.S., 2015. Hydrodynamic constraints and storm wave characteristics on a sub-horizontal platform. Earth Surf. Process. Landf. 40, 65-77.

Pequignet, A.C.N., Becker, J.M., Merrifield, M.A., Aucan, J., 2009. Forcing of resonant modes on a fringing reef during tropical storm Man-Yi. Geophys. Res. Lett. 36, L03607.

Pequignet, A.C.N., Becker, J.M., Merrifield, M.A., 2014. Energy transfer between wind waves and low-frequency oscillations on a fringing reef, Ipan, Guam. J. Geophys. Res. 119, 6709-6724.

Poate, T., Masselink, T., Austin, M., Dickson, M., Kench, P., 2016. Observations of wave transformation on macro-tidal rocky platforms. J. Coast. Res. SI75, 602-606.

Poate, T., Masselink, G., Austin, M.J., Dickson, M., McCall, R., 2018. The role of bed roughness in wave transformation across sloping rock shore platforms. J. Geophys. Res. 123, 97-123.

Pomeroy, A., Lowe, R., Symonds, G., van Dongeren, A., Moore, C., 2012. The dynamics of infragravity wave transformation over a fringing reef. J. Geophys. Res. 117, C11022.

Roelvink, D., Reniers, A., van Dongeren, A., van Thiel de Vries, J., McCall, R., Lescinski, J., 2009. Modelling storm impacts on beaches, dunes and barrier islands. Coast. Eng. 56, 1133-1152.

Ruessink, B.G., 1998. The temporal and spatial variability of infragravity energy in a barred nearshore zone. Cont. Shelf Res. 18, 585-605.

Ruju, A., Lara, J.L., Losada, I.J., 2012. Radiation stress and low-frequency energy balance within the surf zone: a numerical approach. Coast. Eng. 68, 44-55.

Senechal, N., Coco, G., Bryan, K.R., Holman, R.A., 2011. Wave runup during extreme storm conditions. J. Geophys. Res. 116, C07032

Stephenson, W.J., Dickson, M.E., Denys, P.H., 2017. New insights on the relative contributions of coastal processes and tectonics to shore platform development following the Kaikōura earthquake. Earth Surf. Process. Landf. 42 (13), 2214-2220.

Sunamura, T., 1992. Geomorphology of Rocky Coasts. Wiley, New York.

Symonds, G., Huntley, D., Bowen, A.J., 1982. Two-dimensional surf beat: long wave generation by a time-varying breakpoint. J. Geophys. Res. 87, 492-498.

Trenhaile, A.S., 1974. The geometry of shore platforms in England and Wales. Trans. Inst. Br. Geogr. 62, 129-142.

Trenhaile, A.S., 1987. The Geomorphology of Rock Coasts. Oxford University Press, Oxford.

Trenhaile, A.S., 1999. The width of shore platforms in Britain, Canada, and Japan. J. Coast. Res. 15, 355-364

Trenhaile, A.S., 2018. Shore platform erosion and evolution: implications for cosmogenic nuclide analysis. Mar. Geol. 403, 80-92.

Trenhaile, A.S., 2019. Hard-rock coastal modelling: past practice and future prospects in a changing world. J. Mar. Sci. Eng. 7 (34), 1-16.

Van Dongeren, A., Battjes, J., Janssen, T., van Noorloos, J., Steenhauer, K., Steenbergen, G., Reniers, A., 2007. Shoaling and shoreline dissipation of low-frequency waves. J. Geophys. Res. 112, C02011.

Van Dongeren, A., Lowe, R., Pomeroy, A., Trang, D.M., Roelvink, D., Symonds, G., Ranasinghe, R., 2013. Numerical modelling of low-frequency wave dynamics over a fringing coral reef. Coast. Eng. 73, 178-190.

Walkden, M.J.A., Dickson, M.E., 2008. Equilibrium erosion of soft rock shores with a shallow or absent beach under increased sea level rise. Mar. Geol. 251, 75-84. 